\title{
Vulnerabilidad urbana desapercibida e incertidumbre de los métodos estadísticos de identificación
}

\section{Unnoticed urban vulnerability and uncertainty of statistical methods of identification}

\author{
Jesús García-Araque y José Luis García Cuesta \\ Departamento de Geografía, Universidad de Valladolid, España
}

\section{Resumen}

Los métodos estadísticos utilizados habitualmente en España para detectar vulnerabilidad urbana propician que algunos espacios vulnerables pasen desapercibidos. Quienes intervienen en los territorios para garantizar igualdad entre la población se guían por estas acotaciones, por lo que precisan de un método certero. Con el propósito de visibilizar esta falta de fiabilidad se exponen contrariedades que pueden provocarla y se analiza la estimada de mayor trascendencia, que es la discrecionalidad de las metodologías identificatorias, por recurrir distintos autores a métodos e indicadores diferentes y obtener resultados desiguales. Tomando la ciudad de Valladolid como banco de pruebas se han aplicado seis procedimientos relevantes y replicables de identificación, que arrojan resultados dispares. Ante esta falta de fiabilidad se cuestiona la pertinencia de emplear únicamente métodos estadísticos para detectar vulnerabilidad urbana y se reflexiona sobre métodos alternativos.

Palabras clave: Vulnerabilidad urbana, vulnerabilidad desapercibida, calidad de vida, desigualdad social, análisis estadístico.

\section{Abstract}

The statistical methods commonly used in Spain to detect urban vulnerability encourage some vulnerable areas to go unperceived. Those involved in the territories to ensure equality among the population are guided by these dimensions, so they need a certain method. With the purpose of visualizing this lack of reliability are exposed setbacks that can induce and analyzes the estimated of greatest importance, that is the discretion of the methodologies identifying, by relying on different authors to methods and different indicators and get uneven results. Taking the city of Valladolid as a bank of tests have been applied six procedures relevant and replicable of identification, which shed mixed results. In view of this lack of reliability is questioned the relevance of only use statistical methods to detect urban vulnerability and reflects on alternative methods.

Keywords: Urban vulnerability, unnoticed vulnerability, quality of life, social inequality, statistical analysis. 


\section{INTRODUCCIÓN}

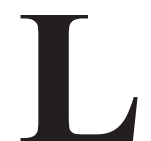

a desigualdad social entre espacios en ciudades es un asunto en expansión y de actualidad, debido al constante crecimiento urbano y a la incidencia de la crisis, por una parte, y por otra a la preocupación política desde que la Unión Europea (UE) manifestó en su agenda de crecimiento "Estrategia Europa 2020" la necesidad de garantizar la cohesión social en los Estados miembros (Comisión Europea, 2010). Todo ello justifica con creces la identificación de la "vulnerabilidad social en ciudades" como objeto de estudio, pues la inacción ante este problema puede impedir el correcto funcionamiento de un territorio y la generación de desigualdades sociales.

Como primer paso de cualquier actuación para garantizar la igualdad social entre espacios, se precisa detectar áreas desfavorecidas socioeconómicamente para posibilitar su ulterior análisis. Diferenciar espacios en función de las características de sus habitantes es la forma habitual de identificación de espacios vulnerables, no obstante, no se ha definido un método común. En todos los casos se recurre a un análisis cuantitativo, basado en métodos estadísticos que diferencia espacios en función de la situación de sus habitantes, atendiendo a una serie de variables. En estudios de esta índole, es frecuente cuestionar los métodos utilizados y que cada autor proponga metodologías, indicadores y escalas diferentes, que pretenden mostrar más su validez que la de otros. Esta diversidad posibilita cuestionarse si todos los métodos usados arrojan similares resultados. En caso de que no ocurra así y las detecciones no alcancen a todos los espacios con población en peor situación que el resto de la ciudad, pasaría inadvertida su situación y podrían verse alejados de intervenciones para mejorar su calidad de vida.

Es evidente la inexistencia de estudios que muestren de forma sistémica las diferencias entre métodos, y dada la imposibilidad de comparar la totalidad de procedimientos aplicados, en este trabajo hemos efectuado una comparativa entre seis metodologías de identificación con vistas a detectar el alcance de las disimilitudes entre resultados. Con el objetivo final de conocer la fiabilidad de los métodos usados para identificar la vulnerabilidad urbana, se ha concretado la revisión en un espacio conocido, sobre el que evaluar, contrastar y validar la bondad de los resultados.

La consecuencia de una elevada disparidad de conclusiones - a pesar de que todos puedan ser métodos igual de válidos - sería que, con independencia del método, no se efectúa una identificación perfecta que alcance a todas las zonas desfavorecidas de la ciudad. De esta forma, es- 
pacios que no son señalados como vulnerables podrían serlo cambiando el método, o incluso, alterando las variables utilizadas o la ponderación que se les asigne, dando lugar a un nuevo método o a una variante del anterior.

Por otro lado, a lo largo del trabajo comprobamos si existe otro método que evite la disparidad de criterios y concite el necesario consenso en cuanto a las variables utilizadas y su ponderación, para lo que se realizará un análisis transversal para evitar el debate, que resulta excesivamente amplio, entre la utilización de perspectivas cualitativa o cuantitativa. A su vez, se harán ineludibles referencias a ventajas y beneficios de ambas perspectivas, con vistas a una posible aplicación de métodos cualitativos de detección.

El trabajo se ha estructurado en un apartado descriptivo, uno empírico y unas conclusiones finales en las que se reflexiona sobre los descubrimientos efectuados y se aportan respuestas al problema planteado. El primero define los conceptos de vulnerabilidad y exclusión, necesarios para comprender el objeto de estudio, e incide en la forma de estudiar la vulnerabilidad urbana. Se han identificado estrategias nacionales de los últimos 20 años, dimensiones de análisis y metodologías de identificación. El estado de la cuestión se presenta mostrando los enfoques de mayor trascendencia, examinando con espacial énfasis el trabajo de Hernández Aja (1997), considerado como punto de inflexión que definió el devenir de las investigaciones posteriores.

El apartado empírico utiliza la ciudad de Valladolid como prueba de ensayo, donde se aplicarán diferentes métodos de identificación replicables en otros espacios. Ha sido seleccionada por su tamaño intermedio y por el conocimiento del entorno, cuestión favorable al requerirse del análisis e interpretación de resultados diversos y contradictorios. La variable tamaño de la ciudad ha sido considerada porque defendemos que las ciudades intermedias han sido poco reconocidas en la investigación urbana, a pesar de estar habitadas por 1,053 millones de personas, que suponen 14.3 por ciento de la población mundial (Llop y Hoeflich, 2016).

La escala de análisis corresponde con lo que en España se conocen como Secciones Censales (SSCC, en adelante). Se trata de la unidad mínima de desagregación para la que el Instituto Nacional de Estadística (INE) ofrece información, y la más utilizada por autores nacionales en el tema abordado. Todo el territorio se encuentra divido en 34,251 SSCC, con una población en cada una de ellas que puede oscilar entre las 500 y dos mil personas, indistintamente de su extensión. 
Para localizar las SSCC desfavorecidas se utilizan seis métodos cuantitativos, que expondremos más adelante. Ciertamente, existen otros muchos, pero se pretende ofrecer una muestra de la diversidad de resultados en función de la fórmula utilizada, mediante los métodos estimados de mayor trascendencia. En ningún momento se juzgan los procedimientos, ya que solo se busca poner de manifiesto la posibilidad de que puedan quedar zonas vulnerables sin localizar en función de la metodología de identificación empleada.

Los resultados obtenidos se muestran mediante mapas y una tabla resumen. La representación cartográfica ha sido realizada mediante herramientas de Sistemas de Información Geográfica, que facilitan interpretar la información y comprender la distribución de los fenómenos investigados. Los datos utilizados han sido facilitados por la Subdirección General de Urbanismo del Ministerio de Fomento, previo requerimiento al Observatorio de Vulnerabilidad Urbana. Se trata de información recopilada por este organismo a partir del Censo de Población y Viviendas de 2011 (INE, 2019).

\section{Aportación de las Ciencias SOCiales al estudio \\ DE LA VULNERABILIDAD URBANA: ESTADO DE LA CUESTIÓN}

La definición de "vulnerabilidad" proporciona subjetividad en su utilización, motivando que pueda tener infinidad de aplicaciones. Su origen latino alude a un indicativo de la cualidad de "vulnerable". El término vulnerabilis deriva de la unión del sustantivo vulnus y la partícula abilis, que puede traducirse como "que puede producir una herida". La Real Academia Española define vulnerable como "que puede ser herido o recibir lesión, física o moralmente" (RAE, 2018). Por tanto, "vulnerabilidad" hace referencia a la susceptibilidad de ser lastimado física o moralmente.

La amplitud del significado permite su aplicación en multitud de situaciones. En la disciplina geográfica, el término ha sido ampliamente utilizado en dos vertientes. Por una parte, en relación con la vulnerabilidad de personas y sociedades ante desastres naturales (Calvo, 1984), entendiéndose como la predisposición humana a resultar dañada. Por otra, al igual que en el conjunto de las ciencias sociales, se propende a su vinculación con la posibilidad de que las personas sean susceptibles de padecer un daño a consecuencia del impacto de transformaciones sociales (Ruiz, 2011), dando lugar al concepto de "vulnerabilidad social". Este planteamiento comienza a ser utilizado por autores anglosajones, entre los que destacan Chambers y Longhurst, quienes en sus investigaciones sobre po- 
blación rural de los años setenta, entienden que el posible daño que pueden ocasionar las transformaciones externas de carácter económico, político o social, puede traducirse en un deterioro de las condiciones y nivel de vida (Pizarro, 2001).

Acrecentando la definición de vulnerabilidad social más allá de las consecuencias de la exposición a un riesgo, la ONU amplió la forma de entender el problema desde 2003, al añadir los mecanismos y estrategias de la población para afrontar las amenazas o riesgos que podrían herirlos moral o físicamente. De esta forma, lo define como “...estado de elevada exposición a determinados riesgos e incertidumbres, combinado con una capacidad disminuida para protegerse o defenderse de ellos y hacer frente a sus consecuencias negativas" (ONU, 2003: 8). Esta acepción es la más utilizada en el ámbito científico para definir actualmente la "vulnerabilidad social". Unifica la concepción literal del término "vulnerabilidad", las consecuencias del riesgo y la capacidad de prevenir, resistir o sobreponerse a un impacto. Con ello, se entiende que son vulnerables aquellos que, además de ser más proclives a sufrir daños, cuentan con mayores dificultades para prevenirlo, o en caso de que la afección sea inevitable, tienen más dificultades para enfrentarse o sobreponerse a él (Alguacil et al., 2014). Por tanto, la vulnerabilidad social sería el resultado de la interacción entre factores externos, tales como transformaciones socioeconómicas y/o políticas, y entre factores internos, como pueden ser la capacidad de reacción, respuesta o adaptación.

No se puede obviar que el concepto anterior tiene similitud con la "exclusión social", a la que se hace preciso aludir dada su elevada relación con la vulnerabilidad, su amplio uso en estudios de problemáticas sociales y la tendencia a equipar ambos términos. ${ }^{1}$ Los expertos plantean diferentes aproximaciones que, en líneas generales, coinciden en apuntar a quienes no participan en plenitud de sus deberes y derechos sociales y no se benefician de igual forma que los demás ciudadanos del estado de bienestar (Castells, 2005; Laparra et al., 2007).

$\mathrm{Al}$ igual que ocurre con la vulnerabilidad, cada autor incorpora para su cuantificación variables destinadas a medir la calidad de vida, con especial incidencia en aspectos relacionales y de participación, como se observa en trabajos pioneros (Commins, 1993; Laparra et al., 1996; Paugam, 1996) y en estudios nacionales más recientes (Jiménez et al., 2010; Lorenzo, 2014;

\footnotetext{
${ }^{1}$ Muchos textos reflejan equiparación entre la vulnerabilidad y la exclusión social. Sirva como ejemplo el Plan Nacional de Acción de Inclusión Social 2013-2016 (MSSSI, 2014: 57), donde los autores son plenamente conscientes de las diferencias, como demuestran otros apartados del documento.
} 
Llano, 2017). Su principal diferencia con la vulnerabilidad radica en que no precisa de riesgos ni impactos, sino que se refiere a una tesitura contrastada. La vulnerabilidad puede considerarse un paso previo, como una "antesala de la exclusión" (Alguacil, 2006; Malgesini, 2013).

Entendiendo las situaciones sociales en que puede encontrarse un individuo o grupo como un proceso, la vulnerabilidad sería una situación que puede desembocar en exclusión. Así lo entienden documentos oficiales como el Plan Nacional de Acción Social 2013-2016 (MSSSI, 2014), y europeos, como la Comunicación que instaura la Plataforma contra la Pobreza y la Exclusión, que alude reiteradamente a la protección de los vulnerables para reducir la exclusión (Comisión Europea, 2010). Estas impresiones son compartidas por Hernández Aja (1997) que entiende la necesidad de actuar sobre la vulnerabilidad para evitar que se alcance una situación crítica de exclusión.

\section{Una primera aproximación al concepto de vulnerabilidad: los indicadores percibidos}

Entendemos que no existe gran controversia sobre la definición de vulnerabilidad social, más allá de meras puntualizaciones. Sin embargo, el desacuerdo sobre su medición es total. La alusión a una reducción del bienestar o calidad de vida incorpora complejidad, al tratarse de conceptos de difícil cuantificación. Sin entrar en la definición de dichas nociones, se observa que para su medición se precisa de variables destinadas a comparar personas, categorizando el desarrollo de la experiencia vital. Predominan las corrientes de pensamiento objetivas, que establecen necesidades universales relacionadas con una vida satisfactoria o "digna". Por añadidura, una corriente subjetiva atiende al establecimiento de preguntas individualizadas en cada situación.

El debate sobre el catálogo de carencias para medir el bienestar objetivo es excesivamente amplio, pero se estima preciso referirse a su multidimensionalidad y a la falta de consenso para su medición, al motivar que conceptos relacionados, como la vulnerabilidad, pasen a ser igualmente complejos. En el estado actual del conocimiento, resulta inviable elaborar un sistema de indicadores que englobe todos los elementos que forman parte de la complejidad del ámbito humano.

Las primeras evaluaciones objetivas atendían al factor económico (Kuznets, 1934), utilizando el Producto Interno Bruto (PIB) y el Producto Interno Bruto percápita (PIBpc). Pese a que comenzó a aplicarse una perspectiva multidimensional desde los años setenta (UNRISD, 1972), no fue 
hasta el trascendental primer informe sobre desarrollo humano (Ul Haq, 1990), que mide el bienestar mediante el Índice de Desarrollo Humano (IDH) atendiendo a la educación, salud e ingresos, cuando se instaura la idea. Desde entonces han surgido múltiples propuestas que, en ocasiones, enuncian indicadores de difícil cuantificación. Autores pioneros como Doyal y Gough (1991) sugieren reparar en factores subjetivos, al atender al riesgo de sufrir carencias de atención, salud o relación. La escala de calidad de vida de Schalock (1993), revisada por Verdugo, Arias et al. (2007), es una de las más utilizadas internacionalmente. Propone siete dimensiones de carácter subjetivo, de un total de ocho.

Actualmente, es generalizada la tendencia a conjuntar factores, materiales e inmateriales, reparando en abundantes indicadores. Organizaciones internacionales promueven alejarse del enfoque económico y recurrir a gran número de variables. El Instituto Nacional de Estadísticas (INE) reseña la implicación de la Organización para la Cooperación y el Desarrollo Económico (OCDE) desde 2004, a raíz de la celebración del foro mundial de Palermo (INE, 2018). La Organización de las Naciones Unidas (ONU) incorpora oficialmente este enfoque en sus debates desde la aprobación de su Resolución 65/309 de 2011: "La felicidad: hacia un enfoque holístico del desarrollo". ${ }^{2}$ En la UE el debate se inició en 2007, tras la conferencia de la Comisión Europea "Más allá del PIB", ${ }^{3}$ que tuvo su continuación en el "Informe sobre la Medición del Desarrollo Económico y del Progreso Social" de Fitoussi, Sen y Stiglitz ${ }^{4}$ (2008), encargado para valorar el PIB como indicador del progreso social. Basándose en él, Eurostat publica desde 2013 indicadores de calidad de vida que actualiza periódicamente. ${ }^{5}$ De igual forma, el INE considera nueve dimensiones, desagregadas en 61 indicadores, enmendados en tres ocasiones (INE, 2018).

Esta constante actualización, que pretende avanzar en el tema, más bien aporta confusión. Para añadir más desconcierto, y paralelamente al desarrollo de esta perspectiva, se promueven operaciones estadísticas armonizadas en la UE que prestan elevada atención a las carencias económicas. Son promovidos desde Eurostat y, en definitiva, analizan la calidad de vida de la población. Es el caso de la Encuesta de Condiciones de Vida, desarrollada por el INE, que atiende desde 2004 a indicadores relativos a empleo, ingresos, pobreza, privación y protección social. Los intentos por

\footnotetext{
2 Enlace a A/RES/65/309 de Naciones Unidas, 25 de agosto de 2011: http://www.un.org/en/ga/ search/view_doc.asp?symbol=A/RES/65/309\&Lang=S

3 Enlace a Comisión Europea www.beyond-gdp.eu

4 Enlace a Informe Stiglitz-Sen-Fitoussi www.eustat.eus/documentos/datos/CV10_03_1.pdf

5 Enlace a Eurostat http://ec.europa.eu/eurostat/web/gdp-and-beyond/quality-of-life
} 
consensuar un sistema único han sido muchos, pero no han alcanzado su objetivo a pesar de crearse organismos exclusivos para ello, como la Red de Instituciones y Expertos en Estadísticas Sociales y de Medio Ambiente, de CEPAL, que desde 2003 tantea consensos sobre indicadores a utilizar internacionalmente.

\section{La vulnerabilidad no percibida en ámbitos urbanos: el reconocimiento de un problema socio-urbano}

Aplicando los criterios y pautas propios de los estudios sobre "vulnerabilidad social" a un ámbito urbano, surge la vulnerabilidad social urbana, alusiva a la predisposición de habitantes o colectivos residentes en ciudades de ser afectados por circunstancias desfavorables que podrían reducir su calidad de vida, con menor posibilidad de defensa o recuperación que otros de la misma ciudad. La definición más ampliamente utilizada en España (entre otros por Subirats y Martí-Costa, 2014), procede del Estudio de Áreas Vulnerables de Ciudades Españolas (en adelante EAVCE) que añade a la definición de Naciones Unidas (2003) una perspectiva psicosocial subjetiva al incluir la reducida esperanza de superar la condición social, consecuencia de la percepción negativa de la propia situación (Hernández Aja, 2010: 4).

La desigualdad social ha sido habitual en la evolución urbana, resultando consustancial a las ciudades (Harvey, 1977). Su dinámica de formación ocasiona división de espacios en función de las características diferenciales de sus pobladores, que viene a generar una plasmación espacial de las desigualdades. La distribución urbana y el consiguiente reparto de sus habitantes suponen una exteriorización de la dinámica interna, que refleja su evolución cambiando a la par de las transformaciones sociales.

Cabría pensar que los ciudadanos más vulnerables podrían repartirse heterogéneamente, sin embargo, tienden a concentrarse en áreas diferenciadas del espacio circundante, que asisten a un deterioro social, demográfico, económico y arquitectónico, sin que ningún organismo actúa sobre ellas. La connatural fragmentación espacial, así como su asociación con las transformaciones sociales, da lugar a que los espacios desfavorecidos varíen su cantidad y extensión en función del contexto económico. De esta forma, las etapas de debilidad económica motivan su expansión, como ha ocurrido desde la irrupción de las crisis de 2008, que ha generado mayor segregación.

Las ciudades han sido históricamente las áreas humanizadas donde las relaciones sociales han generado una distribución menos igualitaria (Te- 
mes, 2014). Son muchos los problemas a los que se enfrenta la población urbana que, combinados entre sí, generan un problema integral. La cuantiosa y dinámica diversidad de factores que afectan a las ciudades y a sus habitantes convierten al hecho urbano en algo complejo y en constante evolución y, a consecuencia de ello, difícil de estudiar, como así indica David Harvey al entender que "la ciudad es, manifiestamente, algo muy complicado" (Harvey, 1977: 15).

Muchos autores opinan que los habitantes urbanos tienen mayor predisposición a la vulnerabilidad que los rurales (Pizarro, 2001; Alguacil, 2006; Temes, 2014). Autores tan prestigiosos como Élisée Reclus anticipaban el fin de las ciudades a mediados del siglo XIX, mostrando preocupación por la situación de los urbanitas (Reclus, 1866, citado por Homobono, 2009). La preocupación por la dicotomía campo-ciudad se mantiene 150 años después. El gobierno regional de la Comunidad de Madrid, en su Decreto 73/1990, de 19 de julio, que aprueba el ingreso madrileño de integración, señaló que, paralelamente al periodo de crecimiento, se producen desigualdades que "adquieren mayor gravedad en los núcleos urbanos" (Decreto 73/1990, BOCM 25: preámbulo).

La complejidad de los estudios urbanos constatada por Harvey puede, entre otras cuestiones, motivar que una parte de la población desfavorecida no sea localizada. En esta línea, algunos autores, plantean la existencia de una vulnerabilidad invisible. A pesar de no compartir dicho concepto al referirse a aquello que no se ve, y estimar más apropiado referirnos a una vulnerabilidad desapercibida, que puede verse, pero no se aprecia y pasa inadvertida, en todo caso ambos conceptos hacen referencia a la existencia de colectivos no detectados, que ven limitadas sus oportunidades de protección y obstaculizada la corrección de las desigualdades. Este problema ha sido insuficientemente atendido y cuenta con escasos trabajos de investigación. Algunos autores han constatado su presencia, pese a que no lo analizan en profundidad, y son pocos quienes intentan localizarlo espacialmente (Metzger y D'Ercole, 2009; Menchaca, Cervantes et al., 2010). Arcos et al. (2016) dan un paso más al distinguir una vulnerabilidad invisible para los propios excluidos, que pueden ser inconscientes de su situación.

En relación con la vulnerabilidad desapercibida, podemos encontrar términos como "pobreza invisible". A escala regional, la Red Andaluza de Lucha contra la Pobreza y la Exclusión Social (EAPN-A, 2016) ha denunciado su existencia mediante una campaña informativa referida a una pobreza multidimensional no percibida socialmente porque, según indican, los pobres no visten con harapos, ni viven en chabolas. Otros estudios, cen- 
trados en el ámbito local, apuntan a una extensión invisible de la pobreza monetaria. Beytía (2012) la detectó en campamentos chilenos al analizar la satisfacción con la vida de los residentes.

Evidenciado el problema, se puede afirmar que coexisten diferentes tipos de vulnerabilidad desapercibida en las ciudades. Ante la ausencia de un análisis sistemático, se muestra en la Tabla 1 una clasificación de categorías que refleja motivos por los que un colectivo desfavorecido puede no ser detectado. Ha sido elaborada a partir de literatura científica sobre la materia y de los resultados de nuestras investigaciones sobre la identificación de la vulnerabilidad en ciudades. Por una parte, como indica EAPN-A, la percepción social puede producir invisibilidad si no es externalizada o percibida como tal. Por otra parte, Menchaca, Cervantes y Bueno (2010) aluden a una vulnerabilidad aislada de las estadísticas oficiales por carencia de datos.

Tabla 1: Tipologías de vulnerabilidad desapercibida

\begin{tabular}{|l|l|}
\hline \multirow{4}{*}{$\begin{array}{l}\text { Vulnerabilidad desapercibi- } \\
\text { da por la percepción social }\end{array}$} & $\begin{array}{l}\text { Nuevas vulnerabilidades, que no son percibidas } \\
\text { como tales }\end{array}$ \\
\cline { 2 - 3 } Vulnerabilidad desapercibi- & Vulnerabilidades no externalizadas. \\
\hline \multirow{5}{*}{ da en estadísticas oficiales } & $\begin{array}{l}\text { Vulnerabilidad extrema (entre otros: población } \\
\text { sin hogar o sin papeles, viviendas ocupadas) }\end{array}$ \\
\cline { 2 - 2 } & $\begin{array}{l}\text { Espacios vulnerables de reducido tamaño (meno- } \\
\text { sestudie) }\end{array}$ \\
\cline { 2 - 2 } & Carencia de datos \\
\cline { 2 - 2 } & Metodología identificativa inadecuada \\
\cline { 2 - 2 } & $\begin{array}{l}\text { Posibles divergencias en función de la metodolo- } \\
\text { gía identificativa }\end{array}$ \\
\hline
\end{tabular}

Fuente: elaboración propia.

Como se indica en los capítulos 3 y 4, la escala de trabajo es una variable primordial, ante la dificultad de obtener datos de escalas reducidas. De igual forma, resulta evidente que la carencia de datos dificulta la localización de la vulnerabilidad más extrema, al tratarse de población que, entre otras cuestiones, puede encontrarse en situación irregular, residir en viviendas ilegales o incluso carecer de residencia. Finalmente, la metodología utilizada para distinguir territorios puede dejar algunos fuera de la identificación. No puede negarse que existe la posibilidad de utilizar una 
metodología inadecuada, pero, sin entrar a valorar cual puede ser la adecuada, la falta de consenso lleva a que cada una identifique diferentes espacios como vulnerables. Dilucidar la eventual existencia de este último tipo de vulnerabilidad desapercibida es el tema principal del presente trabajo.

\section{IDENTIFICACIÓN DE LA VULNERABILIDAD EN LAS CIUDADES ESPAÑOLAS A PARTIR DE RECOMENDACIONES DE LA OCDE}

Los trabajos nacionales de mayor trascendencia que investigan Áreas Urbanas Vulnerables, cuyas características y enfoque han sido ampliamente replicadas por otros autores nacionales, son elaborados por la Sección de Urbanismo del Instituto Juan de Herrera de la Universidad Politécnica de Madrid. Desde esta institución, bajo el impulso del Ministerio de Fomento, se han desarrollado diversos proyectos, entre los que destacan los Estudios de Áreas Vulnerables de Ciudades Españolas (EAVCE), que identifican y caracterizan espacios desfavorecidos mediante un enfoque multidimensional y territorial (Hernández Aja, 1997, 2007, 2010).

El estudio de 1997 formaba parte de una petición de la OCDE, que reclamó la participación de diez países en un proyecto para analizar áreas urbanas desfavorecidas. El resultado fue el informe "Integrating Distressed Urban Areas" (OECD, 1998), para el que España sintetizó tres trabajos ${ }^{6}$. Uno de ellos fue el mencionado de Hernández Aja, 1997) cuya continuación dio lugar a una gran producción científica y a la creación del portal web "Observatorio de la Vulnerabilidad Urbana", ${ }^{7}$ que aloja estudios y enlaces a otras plataformas. Sobresalen el "Catálogo de áreas vulnerables", que presenta información estructurada relativa a barrios urbanos vulnerables analizados con datos de los censos 1991, 2001, 2011 y del padrón municipal de 2006 (INE, 2019); y el "Atlas de la Vulnerabilidad Urbana", con mapas temáticos e información estadística a escala de sección censal de los más de ocho mil municipios españoles. La información estadística y, como consecuencia, los indicadores de ambos, han servido de base a otros estudios al tratarse de datos oficiales.

\footnotetext{
6 "Estudio cuantitativo sobre barrios desfavorecidos en las ciudades españolas" (1995), que estudiaba SSCCs desfavorecidas en municipios de 20 mil a 50 mil habitantes; "La intervención pública en áreas urbanas vulnerables" (1996), que analizaba cualitativamente políticas de intervención; y el "Análisis urbanístico de barrios desfavorecidos" (1997), que sintetizaba un trabajo de investigación que analizó SSCCs de 88 ciudades.

7 Enlace a Observatorio de la vulnerabilidad Urbana: https://www.fomento.es/arquitectura-vivienda-y-suelo/urbanismo-y-politica-de-suelo/observatorio-de-la-vulnerabilidad-urbana

8 Enlace a Catálogo de Barrios Vulnerables: https://apps.fomento.gob.es/barriosvulnerables

9 Enlace a Atlas de la Vulnerabilidad Urbana: http://atlasvulnerabilidadurbana.fomento. es/\#l=es; $=$ map2
} 
Tabla 2: Indicadores Básicos de Vulnerabilidad Urbana de los Estudios de Áreas Vulnerables de Ciudades Españolas

\begin{tabular}{|c|c|c|c|}
\hline $\begin{array}{l}\text { Datos de } \\
\text { referencia }\end{array}$ & $\begin{array}{l}\text { Año de } \\
\text { publicación }\end{array}$ & IBVU & Valor de referencia \\
\hline \multirow{5}{*}{$\begin{array}{l}\text { Censo } \\
1991\end{array}$} & \multirow{5}{*}{1997} & $\begin{array}{l}\text { Porcentaje población } \\
\text { desempleada }\end{array}$ & $\geq($ media nacional $* 1,5)$ \\
\hline & & $\begin{array}{l}\text { Porcentaje mayores } \\
\text { de } 16 \text { sin estudios o } \\
\text { analfabetos }\end{array}$ & $\geq($ media nacional $* 1,5)$ \\
\hline & & $\begin{array}{l}\text { Porcentaje viviendas } \\
\text { sin baño o ducha dentro }\end{array}$ & $\geq($ media nacional $* 2)$ \\
\hline & & $\begin{array}{l}\text { Porcentaje viviendas } \\
\text { sin retrete dentro }\end{array}$ & $\geq($ media nacional $* 2)$ \\
\hline & & $\begin{array}{l}\text { Porcentaje viviendas } \\
\text { sin agua corriente }\end{array}$ & $\geq($ media nacional $* 2)$ \\
\hline \multirow{3}{*}{$\begin{array}{l}\text { Censo } \\
2001\end{array}$} & \multirow{3}{*}{2010} & $\begin{array}{l}\text { Porcentaje población } \\
\text { desempleada }\end{array}$ & $\geq($ media nacional $* 1,5)$ \\
\hline & & $\begin{array}{l}\text { Porcentaje mayores } \\
\text { de } 16 \text { sin estudios o } \\
\text { analfabetos }\end{array}$ & $\geq($ media nacional $* 1,5)$ \\
\hline & & $\begin{array}{l}\text { Porcentaje población } \\
\text { en viviendas sin servi- } \\
\text { cio o aseo }\end{array}$ & $\geq($ media nacional $* 2)$ \\
\hline $\begin{array}{l}\text { Padrón } \\
2006\end{array}$ & 2007 & $\begin{array}{l}\text { Porcentaje extranjeros } \\
\text { no pertenecientes a la } \\
\text { UE }\end{array}$ & $\geq($ media nacional $* 2)$ \\
\hline \multirow{3}{*}{$\begin{array}{l}\text { Censo } \\
2011\end{array}$} & \multirow{3}{*}{$\begin{array}{l}\text { Sin realizar } \\
\text { (accesi- } \\
\text { ble en el } \\
\text { Catálogo de } \\
\text { Barrios vul- } \\
\text { nerables) }\end{array}$} & $\begin{array}{l}\text { Porcentaje población } \\
\text { desempleada }\end{array}$ & $\geq($ media nacional $* 1,5)$ \\
\hline & & $\begin{array}{l}\text { Porcentaje mayores } \\
\text { de } 16 \text { sin estudios o } \\
\text { analfabetos }\end{array}$ & $\geq($ media nacional $* 1,5)$ \\
\hline & & $\begin{array}{l}\text { Porcentaje viviendas en } \\
\text { ruina o malas condi- } \\
\text { ciones }\end{array}$ & $\geq($ media nacional $* 2)$ \\
\hline
\end{tabular}

Fuente: elaboración propia a partir de Hernández Aja (1997, 2010 y 2007).

El trabajo dirigido por Hernández Aja (1997) para la OCDE posibilitó la difusión “oficial” en España de la perspectiva multidimensional de la marginalidad urbana. La OCDE propuso comparar desempleo y renta 
respecto de la media nacional, sugiriendo indicadores correlacionados en ausencia de información. La identificación fue mayoritariamente cuantitativa, contrastada cualitativamente. Se basó en variables del Censo de 1991 a las que se denominó "Indicadores Básicos de Vulnerabilidad Urbana" (IBVU), que variaron en cada estudio en función de los datos disponibles. Se clasifica como desfavorecida una SSCC que supera un valor de referencia en al menos un indicador de los mostrados en la Tabla 2. Seguidamente, se establecieron áreas estadísticas vulnerables agrupando SSCC entre tres mil y 15 mil habitantes. Se rehicieron los contornos reparando en una observación subjetiva, que el principal artífice de los EAVCE juzgó deficiente en un trabajo posterior (Hernández Aja, 2007). No en vano, al aplicarla, se descartaron 36 de las 139 ciudades contempladas por no poseer áreas con los criterios definidos. Una vez finalizada la identificación, se analizaron las zonas delimitadas mediante 50 indicadores agrupados en: demografía, educación, laboral, vivienda y estructura del hogar.

Hernández Aja (2010) actualizó el primer trabajo identificando y caracterizando las zonas desfavorecidas atendiendo a 68 indicadores clasificados entorno a vulnerabilidad sociodemográfica, socioeconómica, residencial y subjetiva. Ante el incremento de los flujos migratorios, se efectuó otro trabajo (Hernández Aja, 2006) utilizando población inmigrante como única variable identificativa al estimarse que tenían mayor tendencia a la fragilidad.

Desde inicios del siglo XXI, los estudios nacionales apuntan características básicas que prosiguen con la propuesta de Hernández Aja (1997). Inciden en la polidimensionalidad, con una tendencia común a incorporar variables diferentes en cada proyecto - en función de la disponibilidad de datos-, agrupados en ejes. Cada trabajo aporta los indicadores que considera pertinentes, al tiempo que se han planteado multitud de debates al respecto (véase, entre otros, Navarro y Larrubia, 2006; Domínguez-Berjón, 2008).

No obstante, se estima que, ante la variedad de indicadores y la tendencia a incorporar los propios, puede tratarse de un debate infructuoso. El propio EAVCE comprende la dificultad de obtener datos estadísticos actualizados, especialmente a escala supramunicipal, por lo que su disponibilidad se convierte en condicionante fundamental del análisis. Generalmente los datos proceden del censo de población y vivienda, si bien en ocasiones se recurre a datos proporcionados por los respectivos Ayuntamientos. Su disponibilidad y la utilización de métodos estadísticos, rangos y tipologías 
de detección propios, ocasiona que los estudios considerados más relevantes en los últimos tres lustros ofrezcan discordancias metodológicas.

La variabilidad metodológica es inmensa. Puede apreciarse en trabajos eminentemente cuantitativos o cualitativos, y en aquellos que combinan ambos enfoques. Esta última perspectiva es mayoritaria, con tendencia a destinar el apartado cuantitativo a delimitar y el cualitativo a interpretar las áreas detectadas. Entre otros, es utilizada por Palacios (2005) en su acotación de áreas desfavorecidas madrileñas a partir de 13 variables, quien identifica sectores que superan en más de una desviación típica el dato municipal en dos o más indicadores. Complementa el examen con un análisis cualitativo de las zonas desfavorecidas y cuatro estudios de caso. Pérez Quintana (2007) recurre a un análisis de seis variables para identificar la vulnerabilidad, que es ampliado con un apartado cualitativo que contrasta las delimitaciones e identifica problemas. Diferencia distritos desfavorecidos que sobrepasan la media municipal en más de 50 por ciento. Domínguez, Egea, et al. (2008) analizan la vulnerabilidad urbana andaluza mediante 31 variables, agrupadas en ejes y categorías. Simplifican la información mediante un indicador sintético, promediado para generar un indicador único. Establecen como zonas más desfavorecidas las que superan 1,5 desviación típica del promedio andaluz. Una vez identificadas, se analizan estadística y subjetivamente mediante cuatro estudios de caso.

El diagnóstico de Alzola (2011) aborda la identificación mediante un análisis cluster de ocho agrupaciones, a partir de 65 indicadores, reducidos a 16 mediante operaciones estadísticas. El análisis cualitativo contrastó los resultados y compendió problemas e intervenciones. También recurre Pedro Uceda (2016) al análisis cluster y a reducir los indicadores iniciales, de 31 a cinco. Los sintetiza en un índice elaborado mediante Componentes Principales, a partir del cual diferencia barrios vulnerables de tres formas: análisis cluster, superación de una desviación típica de la media municipal, y fijación del cuarto y quinto quintiles como rangos diferenciadores. El apartado cualitativo complementario estudia movimientos sociales.

Con menor preponderancia que la metodología híbrida se presenta una orientación cuantitativa, en la que se detectan igualmente gran cantidad de acciones. El principal artífice de los proyectos del Ministerio de Fomento (Hernández Aja, 2007) utiliza un método propio en un informe para el Ayuntamiento de Madrid. Compara 15 variables con la media regional, municipal y del Centro de la ciudad. Considera vulnerables a las SSCC que superan la comparativa en 50 por ciento. En función de combinaciones en 
la superación de umbrales, estableció vulnerabilidades en cada dimensión y globalmente.

En el marco del estudio de barrios desfavorecidos andaluces (Domínguez, Egea et al., 2008), los mismos autores utilizaron posteriormente la ciudad de Granada como banco de pruebas (Domínguez, Egea et al., 2009), incorporando otros métodos. Las SSCC desfavorecidas se analizan mediante coeficientes de correlación lineal, a partir de los que se obtienen tipologías. Temes (2014) distingue 30 indicadores que sintetiza en un análisis de componentes principales generando cuatro indicadores sintéticos. Determina umbrales críticos a partir de una desviación típica de la media municipal, y tipos de vulnerabilidad distinguiendo si se incide en uno, dos o tres tipos de vulnerabilidad. En los estudios cuantitativos más recientes se mantiene la tendencia diversificadora. Para identificar barrios vulnerables, Piñeira, González y Lois (2017) efectúan componentes principales.

Haciendo referencia directa a los EAVCE, sintetizan sus tres mismas dimensiones, aunque subdivididas en ocho indicadores. Se reseñan las SSCC que superan el valor de " 1 " en uno de los componentes. Los resultados son interpretados mediante una escala polícroma. Duran Gil (2017) distingue 24 variables que combinan problemáticas socioeconómicas y del medio físico. Antes de crear índices, analiza cada variable mediante un análisis exploratorio de datos espaciales, a través del estadístico espacial I de Moran. Seguidamente, crea índices compuestos para cada dimensión y uno global, adicionando cada indicador equiponderado, para adicionar cada dimensión en el índice global.

Resultan escasos los trabajos con prevalencia cualitativa, que en ningún caso delimitan cualitativamente. Son habituales cuando la acotación ha sido consumada de antemano y se busca un acercamiento a la realidad demarcada. Es un procedimiento habitual en Planes municipales orientados a desarrollar áreas urbanas. Entre los muchos existentes, se puede destacar el Plan para recuperar la zona norte de Alicante (Ayuntamiento de Alicante, 2008). Incorpora un diagnóstico con dimensiones e indicadores de desfavorecimiento e investiga la percepción social de los problemas.

Con delimitación predefinida, se han elaborado trabajos híbridos con predominio de la parte subjetiva que evidencian un mayor acercamiento a la realidad urbana que los que carecen de ella. En el diagnóstico de barrios sevillanos de Fuentes Ruiz et al. (2011) predomina un procedimiento basado en entrevistas, complementado por un análisis estadístico que compara cada barrio con la media de la ciudad. El prevalente apartado subjetivo identifica problemas y utiliza el resultado como refuerzo en tomas de 
decisiones. Se incorpora como novedad un análisis $\mathrm{DAFO}^{10}$ que, ante la consideración de la vulnerabilidad como el resultado de la interacción de agentes externos e internos que aportan influencias negativas y positivas, se muestra como una herramienta de gran interés.

\section{VARIACIÓN DE LAS ZONAS VULNERABLES EN FUNCIÓN DE LOS CAMBIOS}

\section{EN LA METODOLOGÍA UTILIZADA PARA SU IDENTIFICACIÓN: EL CASO DE}

\section{LA CIUDAD DE VALLADOLID}

No cabe duda de que se aplica una ingente cantidad de métodos para identificar espacios vulnerables en España, pero queda por saber si el resultado de emplear diferentes procedimientos en un mismo territorio arroja resultados afines o, al menos, aproximados. Si no son análogos, determinados espacios pueden quedar fuera de la identificación, cuando la precisión en este tipo de estudios debiera ser una cuestión básica dada su trascendencia para los habitantes implicados.

Con objeto de averiguar los efectos de la diversidad metodológica, se han detectado espacios vulnerables en la ciudad de Valladolid mediante seis procedimientos identificativos diferentes, desarrollados con el programa informático SPSS Statistics, y que revelan cómo leves cambios metodológicos dan lugar a resultados extremadamente diferentes entre sí.

Las variables que se han utilizado para las diferentes identificaciones proceden del Censo de Población y Vivienda de 2011 (INE, 2019), como se explicó anteriormente. Puesto que el Atlas de Vulnerabilidad es un referente en el tema, se han tomado los 17 indicadores utilizados en sus mapas temáticos referidos a 2011, sobre los que se puede ver su descripción en la página web del Ministerio de Fomento (véase enlace en nota 9).

Dada la reducida escala de desagregación que se utiliza, son muchos los indicadores con carencias en sus datos, para lo que el Instituto Nacional de Estadística alega "protección de la privacidad". Aun siendo conscientes de esta insuficiencia, hemos optado por desarrollar el trabajo con esta información al ser la misma que han manejado en sus estudios tanto el Ministerio de Fomento como la inmensa mayoría de los autores analizados, que recurren sistemáticamente a los datos del Censo de Población y Viviendas. Este hecho no hace sino enfatizar que la escasez de datos es un problema

${ }^{10}$ El análisis DAFO es conocido en Latinoamérica con las siglas FODA y en países angloparlantes como SWOT. Se trata de una herramienta de análisis que ha sido utilizada durante décadas, si bien, se encuentra un tanto en desuso en los últimos años. Es habitualmente utilizada para diseñar planificaciones estratégicas de empresas o territorios, teniendo en cuenta cuestiones internas y del entorno externo. En España, DAFO es acrónimo de las palabras Debilidades, Amenazas, Fortalezas y Oportunidades. El análisis de las Amenazas y Oportunidades tendría en cuenta el entorno externo, mientras que las Debilidades y Fortalezas atenderían a los factores internos. 
que puede poner en entredicho las identificaciones de vulnerabilidad y generar vulnerabilidad desapercibida en España. Con respecto a Valladolid, se ha descubierto una ingente cantidad de vacíos informativos en las 272 SSCC que componen la ciudad, resumidos en la Tabla 3.

Tabla 3: Validez de los datos del Censo de Población y Vivienda de 2011 en las 272 Secciones Censales (SSCC) de Valladolid

\begin{tabular}{|c|c|c|c|}
\hline $\mathrm{n}^{\mathrm{o}}$ & Indicador & $\begin{array}{r}\text { Porcentaje de } \\
\text { SSCC sin datos }\end{array}$ & $\begin{array}{r}\text { Porcentaje de SSCC } \\
\text { con dato } 0,00\end{array}$ \\
\hline 1 & $\begin{array}{l}\text { Población de } 75 \text { años } \\
\text { o más (\%) }\end{array}$ & 0,0 & 31,3 \\
\hline 2 & $\begin{array}{l}\text { Hogares unipersonales } \\
\text { de más de } 65 \text { años }(\%)\end{array}$ & 0,0 & 9,4 \\
\hline 3 & $\begin{array}{l}\text { Hogares con un adulto } \\
\text { y menores }(\%)\end{array}$ & 0,0 & 26,0 \\
\hline 4 & Población extranjera (\%) & 0,0 & 16,6 \\
\hline 5 & $\begin{array}{l}\text { Población extranjera menor } \\
\text { de } 15 \text { años }(\%)\end{array}$ & 30,2 & 34,7 \\
\hline 6 & $\begin{array}{l}\text { Tasa de paro } 16-65 \text { años (IBVU) } \\
(\%)\end{array}$ & 3,4 & 0,0 \\
\hline 7 & Tasa de paro juvenil (\%) & 37,4 & 32,1 \\
\hline 8 & Tasa de paro juvenil $2(\%)$ & 12,5 & 57,0 \\
\hline 9 & $\begin{array}{l}\text { Ocupados eventuales respecto total } \\
\text { de ocupados }(\%)\end{array}$ & 3,8 & 72,5 \\
\hline 10 & $\begin{array}{l}\text { Ocupados no cualificados respecto } \\
\text { total de ocupados }(\%)\end{array}$ & 3,8 & 8,7 \\
\hline 11 & $\begin{array}{l}\text { Población mayor de } 16 \text { sin estudios } \\
\text { (IBVU) (\%) }\end{array}$ & 0,0 & 7,9 \\
\hline 12 & $\begin{array}{l}\text { Viviendas con menos } \\
\text { de } 30 \mathrm{~m}^{2}(\%)\end{array}$ & 0,0 & 95,8 \\
\hline 13 & $\begin{array}{l}\text { Superficie media por } \\
\text { habitante }\left(\mathrm{m}^{2}\right)\end{array}$ & 0,0 & 0,0 \\
\hline 14 & $\begin{array}{l}\text { Viviendas sin aseo con } \\
\text { inodoro (IBVU) }(\%)\end{array}$ & 0,0 & 88,3 \\
\hline 15 & Viviendas sin baño o ducha (\%) & 0,0 & 90,6 \\
\hline 16 & $\begin{array}{l}\text { Viviendas en mal estado ruina } \\
(\mathrm{IBVU})(\%)\end{array}$ & 0,0 & 61,9 \\
\hline 17 & $\begin{array}{l}\text { Viviendas en edificios construidos } \\
\text { antes de } 1940(\%)\end{array}$ & 0,0 & 92,5 \\
\hline
\end{tabular}

Fuente: elaboración propia a partir de INE, 2019. 
Debe tenerse en cuenta respecto al porcentaje de SSCC con dato igual a " 0.00 ", que pueden existir zonas que no muestren vulnerabilidad en algún indicador, mayormente en los referentes a vulnerabilidades en las viviendas, pero se antoja complicado que ocurra en el resto de los indicadores.

Todos estos factores terminan por provocar que cada autor recurra a distintas variables en función de la disponibilidad, que es diferente en cada ciudad. De esta forma, con vistas a estudiar ciudades diferentes, resulta imposible seguir al pie de la letra los procesos desarrollados por la inmensa mayoría de los autores analizados, con lo que no pueden compararse resultados entre ciudades. Es decir, cada método sirve para la ciudad en la que se aplica. Como excepción, los EAVCE pueden ser replicados al utilizar exclusivamente datos del Censo de Población y Viviendas, accesibles para cualquier investigador.

Teniendo en consideración los mencionados aspectos relativos a los datos, se ha pretendido que, tanto los métodos aplicados en este trabajo, como los indicadores utilizados, permitan replicar el proceso en cualquier ciudad. Por tanto, utilizamos los procedimientos más representativos detectados en la revisión de la cuestión en España, adaptados a los datos del Censo de Población y Vivienda. Pese a las carencias mencionadas anteriormente, se trata de un documento estadístico de gran valor, ya que cumple con una serie de características que le confieren periodicidad, regularidad, exhaustividad y posibilidad de manejo de la información a diferentes escalas, desde las secciones censales, a los distritos, municipios, provincias y regiones.

La utilización de estos datos nos lleva a situar la sección censal como escala mínima de trabajo para la que se dispone de información detallada a nivel espacial. Se trata de fracciones de territorio que dividen administrativamente los municipios con tamaño y número de habitantes relativamente homogéneos, con finalidad electoral y estadística ${ }^{11}$. Su configuración se determina en función de los individuos que pueden votar en una urna durante una jornada electoral y de la capacidad de un agente entrevistador para efectuar encuestas estadísticas en el plazo de dos meses.

El trabajo a escalas reducidas exige ser especialmente cuidadosos con el tratamiento de la información para garantizar la seguridad y el anonimato. Es preciso evitar la difusión de datos que puedan llevar a identificaciones individuales, para lo que el Instituto Nacional de Estadística establece la figura del "Secreto Estadístico", que obliga a eliminar datos cuando puedan

${ }^{11}$ La Ley Orgánica 5/1985, de 19 de junio, del Régimen Electoral General, establece las características de las secciones censales en cuanto a tu tamaño en superficie y volumen de población. 
motivar la pérdida del anonimato de determinados ciudadanos ${ }^{12}$. Precisamente, como se ha mencionado con anterioridad, esta es la principal causa generadora de los déficits de información expuestos en la Tabla 3.

Con objeto de probar diferentes posibilidades y teniendo en cuenta que algunos autores depuran los indicadores - pero otros no lo hacen-, en el método de componentes principales se han utilizado las 17 variables que analizan los EAVCE y el Atlas, mientras que en el análisis cluster se han seleccionado algunas variables para evitar redundancia y reducir, en la medida de lo posible, lagunas en la información. Se han tomado estas decisiones porque se ha detectado que en los análisis que se sintetizan los datos, generalmente mediante la técnica de componentes principales, incorporan gran cantidad de variables sin depurar, como es el caso de Temes (2014) y Domínguez, Egea, et al. (2008). Por otra parte, Uceda (2016) y Alzola (Coord) (2011), en sus análisis cluster depuran de 65 a 16 indicadores y de 31 a 5 , respectivamente.

- Método 1: Método utilizado por los EAVCE, como trabajos de mayor importancia en España, antes de ajustar la delimitación final en función de apreciaciones urbanísticas y subjetivas para unificar SSCC y distinguir barrios.

- Método 2: Resultado final de los EAVCE, después de ajustar la delimitación final en función de apreciaciones urbanísticas y subjetivas, para unificar SSCC y distinguir barrios.

- Método 3: Adaptación del procedimiento de cálculo del IDH, por su elevada difusión y su relación con la calidad de vida.

- Método 4: Componentes principales, ampliamente utilizados por otros autores, que permite sintetizar y determinar un sistema de variables más pequeño que el original.

- Método 5: Análisis Cluster, considerando el cluster más desfavorecido. Técnica ampliamente utilizada por otros autores, dada su idoneidad para clasificar espacios en función de las características de sus habitantes, diferenciando cada territorio según combinaciones de factores.

- Método 6: Análisis Cluster, considerando los dos clusters más desfavorecidos. Al ofrecer como resultado el Método 5 una cantidad de personas vulnerables muy inferior a otros métodos, se ha ampliado la selección a dos agrupaciones espaciales.

${ }^{12}$ La protección del anonimato queda amparada por distintas normas españolas y europeas: Ley 12/1989, de 9 de mayo, de la Función Estadística Pública; Ley Orgánica 15/1999, de 13 de diciembre, de Protección de Datos de Carácter Personal; Reglamento (CE) no 223/2009 del Parlamento Europeo y del Consejo, de 11 de marzo de 2009, relativo a la Estadística Europea. 
Como paso previo a la identificación estadística de la vulnerabilidad, se ha diferenciado el espacio urbano del rural, para tomar en consideración únicamente los sectores urbanos, que suponen 30 por ciento del municipio $(\mathrm{INE}, 2019)^{13}$. Aunque únicamente cuatro SSCC tienen menos de $100 \mathrm{hab} /$ $\mathrm{km}^{2}$, ocupan 138.2 de los $197.4 \mathrm{~km}^{2}$ municipales. Las zonas rurales solo cuentan con 4,345 habitantes, mientras que 30 por ciento del territorio restante aglutina 305,575 habitantes. Se observa en la Figura 1 las dos tipologías de superficies.

La primera detección se ha efectuado siguiendo la metodología de mayor incidencia en España, que es la empleada en el Catálogo de Barrios Vulnerables del Ministerio de Fomento (véase enlace en nota 8) y en los EAVCE (Hernández Aja, 1997, 2007, 2010). Se han diferenciado las SSCC con problemas cuando superan 1.5 veces la media nacional en al menos uno de los tres Indicadores Básicos previstos para analizar el censo de 2011 (ver Tabla 2).

Los niveles a superar por cada SSCC son 42.3 por ciento en el porcentaje de población desempleada, 16.4 por ciento de población sin estudios o analfabeta y 17.5 por ciento de edificios en ruina o conservación deficiente. No obstante, el Catálogo no muestra esos resultados, sino que ofrece en su página web una redelimitación urbanística y subjetiva de los mismos efectuada siguiendo el procedimiento explicado en el apartado 3, lo que da lugar al método de identificación 2, del presente trabajo. Se puede observar en la Figura 2 la diferencia entre los espacios detectados inicialmente y los que finalmente son observados como vulnerables en el Catálogo. Sin entrar a valorar si se trata de un método válido, llama claramente la atención la gran cantidad de zonas vulnerables descartadas tras la redelimitación, por decisión de técnicos municipales o por tener menos de 3,500 habitantes. Se observaron inicialmente 47 SSCC vulnerables con carencias en al menos un Indicador Básico, que acumulaban 46,960 personas. Con pocas excepciones dispersas por el centro de la ciudad, tendían a concentrarse en zonas semicéntricas, especialmente al norte del centro, en la conocida como primera periferia de la ciudad, edificada entre 1960 y 80. La redelimitación posterior identificó $31 \mathrm{SSCC}$, donde desaparecen todas las zonas céntricas para señalar exclusivamente barrios semicéntricos de la primera periferia.

La población residente en la segunda delimitación es difícil de estimar, al no coincidir con áreas estadísticas del censo. Se puede estimar contabi-

13 Pese a que la distinción podría haberse efectuado con datos recientes del INE (2018), es preciso atenerse al año de referencia de los datos utilizados (2011). 
Vulnerabilidad urbana desapercibida e incertidumbre de los métodos estadísticos de identificación / J. GARCÍA y J.L. GARCÍA

Figura 1: Secciones censales urbanas y rurales del municipio de Valladolid

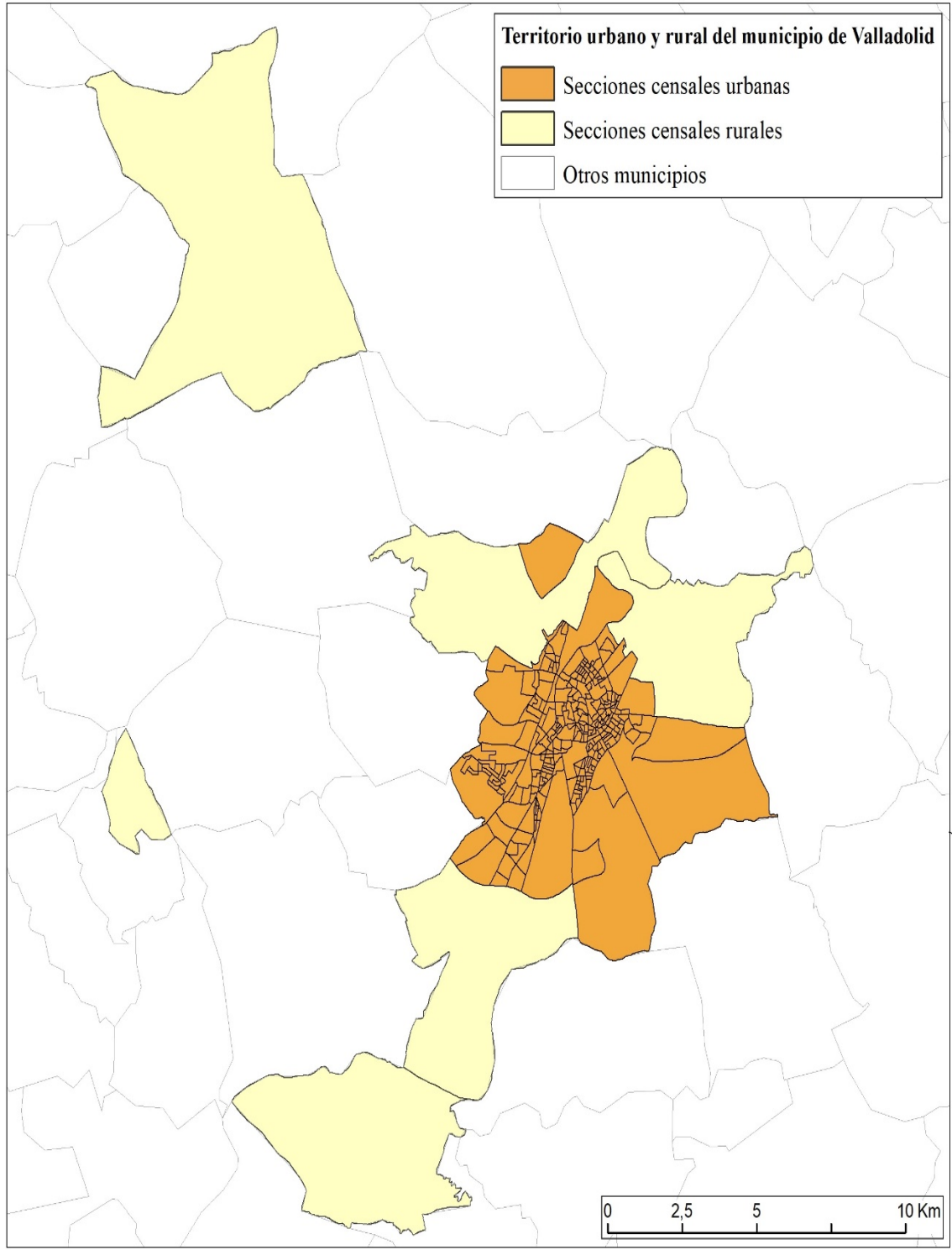

Fuente: elaboración propia. 
Figura 2: Secciones Censales (SSCC) vulnerables en Valladolid según Indicadores Básicos de Vulnerabilidad (IBVU) 2011

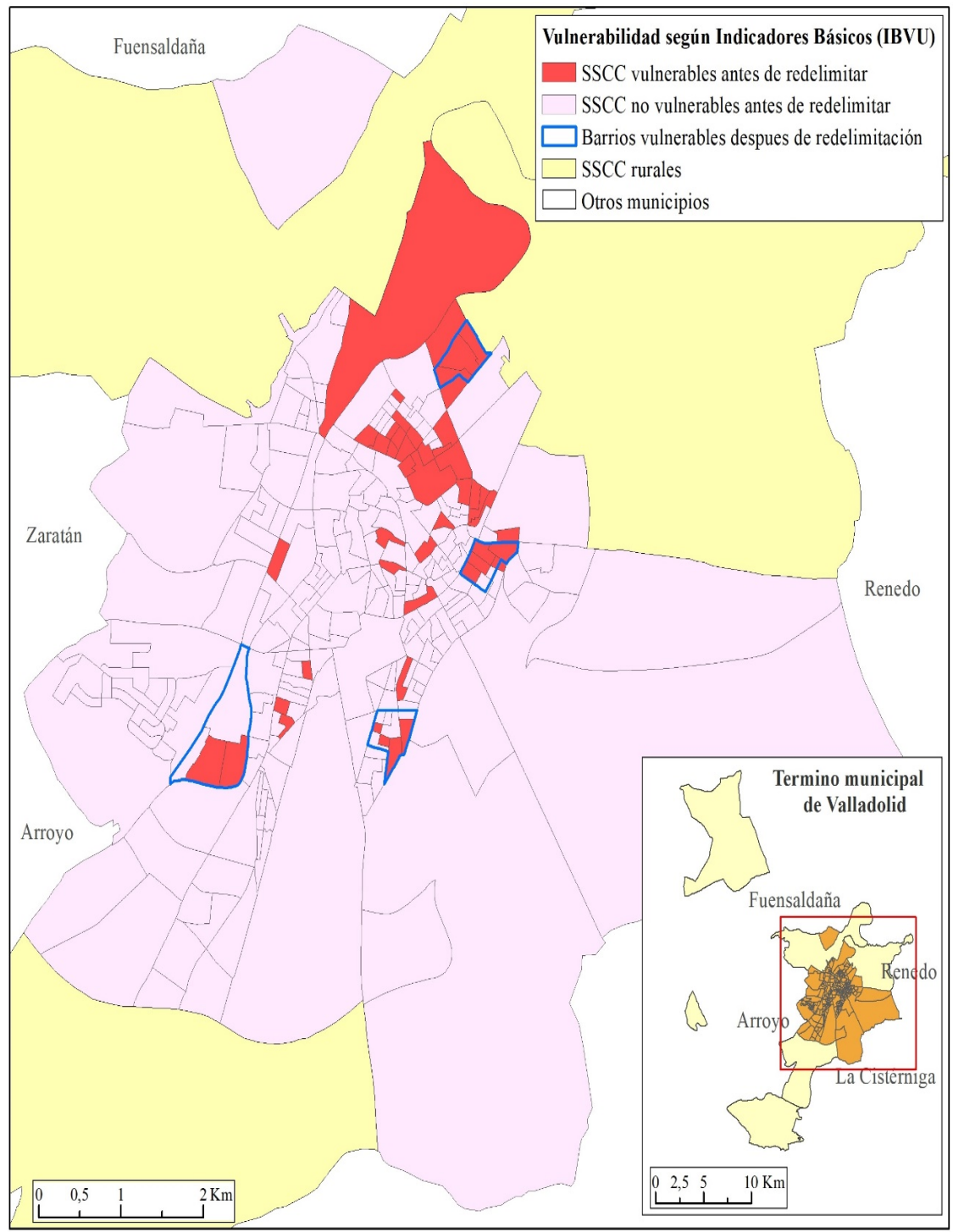

Fuente: elaboración propia. 
lizando el total de población de la SSCC a la que pertenecen los espacios seccionados, que son 21,970 personas y $1.3 \mathrm{~km}^{2}$.

En el siguiente procedimiento se ha aplicado la metodología utilizada para calcular el IDH, que es el indicador más extendido en el mundo para conocer las condiciones de vida de la población. Aunque es un índice utilizado habitualmente para países, considerando que se basa en tres indicadores básicos que pretenden incidir en la calidad de vida —educación, salud, ingresos - y que son los mismos que sugirió la OCDE para elaborar los EAVCE en 1997, es una metodología perfectamente válida para detectar espacios desfavorecidos.

Se crea un índice para cada Indicador Básico del EAVCE que exprese los datos de cada SSCC entre 0 y $1 .{ }^{14}$ A pesar de que el IDH efectúa una media geométrica de los tres índices, se realiza aritmética porque se cuenta con valores " 0 ", que provocarían que el resultado final fuera "0". Como paso final, se establecen cuartiles, de forma que queda el percentil 25 con un valor de 7.5, el percentil 50 con 10.3 y el percentil 75 con 13.2. Los valores situados en el primer cuartil indican vulnerabilidad baja, en el segundo media, en el tercero alta y en el cuarto muy alta. Estos últimos son los espacios reseñados en la Figura 3.

La variabilidad de resultados del Método 2 respecto del proceso anterior es considerable. Aparecen nuevos espacios, situados principalmente en el Este y Suroeste de la ciudad. Al efectuar una media de tres indicadores, el centro de la ciudad queda en mejor situación que considerando un solo factor de vulnerabilidad, como en el método anterior. De esta forma se contabilizan 65 SSCC desfavorecidas, en las que sus 68,690 pobladores sufren de vulnerabilidad muy alta. La superficie aquejada por esta situación se sitúa en $7.5 \mathrm{~km}^{2}$.

Para aplicar el método de los componentes principales se han extraído las variables con el método de regresión. Los 17 indicadores utilizados en el Atlas de Vulnerabilidad Urbana, relativos al censo de 2011, se han sintetizado dando lugar a ocho índices sintéticos. Las variables se han tratado en porcentaje y en relación directa con la vulnerabilidad, excepto el indicador 13 (ver Tabla 4), que estaba en $\mathrm{m}^{2}$ y con relación inversa, por lo que ha sido sometido a un inverso multiplicativo, que lo ha tipificado a la vez que equiparado al resto de índices para que, cuanto mayor sea el dato, revele mayor vulnerabilidad.

\footnotetext{
${ }^{14}$ Se ha aplicado la siguiente fórmula: $\frac{\text { valor real - valor mínimo }}{\text { valor máximo - valor mínimo }}$
} 
Figura 3: Secciones Censales vulnerables según media de Indicadores Básicos

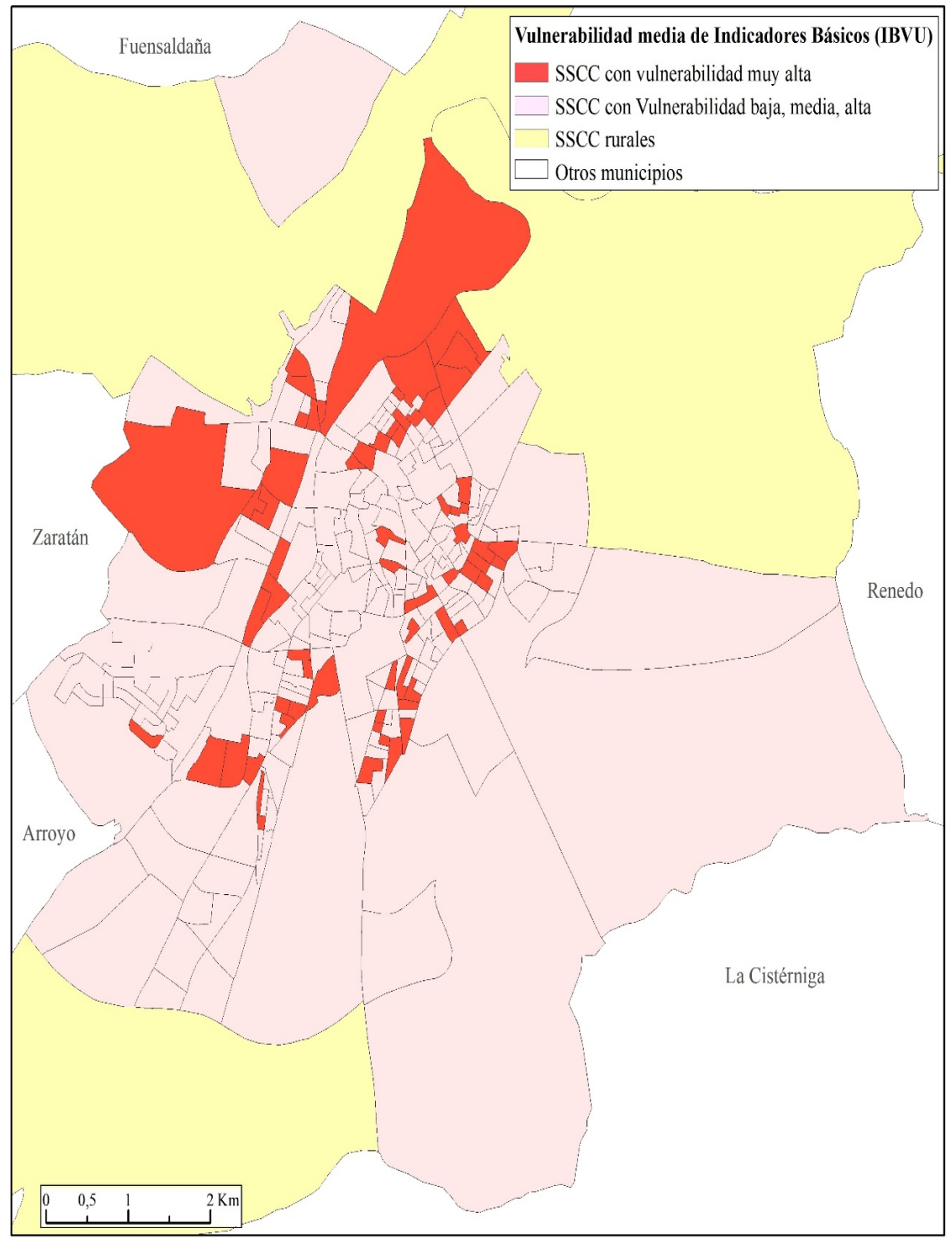

Fuente: elaboración propia. 
Tabla 4: Indicadores del análisis de Componentes Principales y representación de cada componente

\begin{tabular}{|c|c|c|c|c|c|c|c|c|}
\hline \multirow{2}{*}{ Indicadores } & \multicolumn{8}{|c|}{ Componente } \\
\hline & 1 & 2 & 3 & 4 & 5 & 6 & 7 & 8 \\
\hline 1) Mayores de 75 años & 0,05 & 0,72 & 0,41 & $-0,08$ & $-0,25$ & $-0,16$ & 0,11 & 0,07 \\
\hline $\begin{array}{l}\text { 2) Hogares unipersonales } \\
\text { de mayores de } 65 \text { años }\end{array}$ & 0,13 & 0,61 & 0,47 & $-0,14$ & $-0,10$ & $-0,25$ & 0,21 & 0,19 \\
\hline $\begin{array}{l}\text { 3) Hogares con un adulto } \\
\text { y menores }\end{array}$ & $-0,10$ & $-0,31$ & 0,03 & 0,10 & $-0,08$ & 0,08 & 0,63 & 0,53 \\
\hline 4) Población extranjera & 0,78 & 0,02 & $-0,14$ & $-0,13$ & $-0,05$ & $-0,04$ & $-0,03$ & 0 \\
\hline $\begin{array}{l}\text { 5) Población extranjera } \\
\text { menor de } 15 \text { años }\end{array}$ & 0,77 & 0,37 & $-0,46$ & 0,09 & 0 & 0,05 & 0,11 & 0,03 \\
\hline $\begin{array}{l}\text { 6) Desempleo de mayores } \\
\text { de } 16 \text { años }\end{array}$ & 0,45 & $-0,31$ & 0,40 & $-0,21$ & $-0,06$ & 0,08 & $-0,16$ & 0,22 \\
\hline 7) Desempleo juvenil 1 & 0,77 & 0,37 & $-0,46$ & 0,09 & 0 & 0,05 & 0,11 & 0,03 \\
\hline 8) Desempleo juvenil 2 & 0,06 & $-0,31$ & $-0,02$ & 0,41 & $-0,31$ & $-0,31$ & $-0,26$ & 0,45 \\
\hline 9) Ocupados eventuales & $-0,01$ & $-0,02$ & 0,15 & $-0,02$ & 0,66 & $-0,19$ & 0,30 & 0 \\
\hline $\begin{array}{l}\text { 10) Ocupados no } \\
\text { cualificados }\end{array}$ & 0,47 & $-0,33$ & 0,27 & 0,14 & $-0,02$ & $-0,28$ & $-0,10$ & $-0,03$ \\
\hline $\begin{array}{l}\text { 11) Población sin estudios } \\
\text { o analfabetos }\end{array}$ & 0,43 & $-0,06$ & 0,57 & $-0,01$ & $-0,01$ & $-0,03$ & 0,05 & $-0,41$ \\
\hline $\begin{array}{l}\text { 12) Viviendas con menos } \\
\text { de } 30 \mathrm{~m}^{2}\end{array}$ & $-0,13$ & 0,28 & 0,23 & 0,09 & $-0,26$ & 0,70 & $-0,10$ & 0,03 \\
\hline $\begin{array}{l}\text { 13) Superficie media } \\
\text { por habitante }\left(\mathrm{m}^{2}\right)\end{array}$ & 0,62 & $-0,50$ & 0,19 & 0,01 & $-0,03$ & 0,07 & $-0,03$ & $-0,08$ \\
\hline $\begin{array}{l}\text { 14) Viviendas sin aseo } \\
\text { ni inodoro }\end{array}$ & 0,02 & 0,12 & 0,17 & 0,56 & 0,44 & 0,10 & 0,00 & $-0,04$ \\
\hline $\begin{array}{l}\text { 15) Viviendas sin baño } \\
\text { o ducha }\end{array}$ & 0,13 & 0,32 & 0,23 & 0,59 & 0,21 & 0,12 & $-0,25$ & 0,18 \\
\hline $\begin{array}{l}\text { 16) Viviendas en ruina o con } \\
\text { deficiencias constructivas }\end{array}$ & 0,30 & $-0,12$ & 0,15 & $-0,42$ & 0,36 & 0,40 & $-0,09$ & 0,36 \\
\hline $\begin{array}{l}\text { 17) Viviendas construidas } \\
\text { antes de } 1940\end{array}$ & $-0,14$ & 0,32 & $-0,11$ & $-0,35$ & 0,28 & $-0,23$ & $-0,49$ & 0,30 \\
\hline
\end{tabular}

Fuente: elaboración propia (INE, 2019).

A partir de la técnica descrita, se obtienen ocho factores que explican 71.4 por ciento de la varianza total. Como se observa en la Tabla 3, cada factor agrupa más de una problemática — se reseñan valores sobre 0.3 como aquellos con mayor incidencia en cada factor-, por lo que cada componente se convierte en un indicador multidimensional de vulnerabilidad. Se ha determinado como rango a considerar la superación de 1.5 desviaciones típicas con respecto al promedio de la ciudad, que es un umbral 
ampliamente utilizado. Sin embargo, hay que tener en cuenta que algunos autores establecen otros umbrales, por lo que los resultados en caso de elegir otro rango, evidentemente, serían diferentes. Al establecerse en uno la desviación típica de todos los componentes, las SSCC que superen 1.5 en cualquier componente, son consideradas desfavorecidas.

La representación gráfica de los resultados del Método 4 (ver Figura 4), muestra divergencias notables. Gran parte de la vulnerabilidad se sitúa en sectores centrales y en los primeros bordes del centro de la ciudad. Se ha detectado la existencia de una SSCC con valores adversos en cinco de los ocho factores estudiados, de dos en cuatro factores y de nueve en tres factores, como espacios más desfavorecidos. Observando el mapa cabría pensar que se han cometido errores de cálculo, al parecer un inverso de las identificaciones anteriores.

La incorporación de nuevos espacios es debida a la inclusión de factores de desfavorecimiento no considerados anteriormente, como el envejecimiento y la población extranjera. No queremos extendernos en la implicación de ambos aspectos en la vulnerabilidad social, puesto que ya ha sido mencionado por autores prestigiosos (Hernández Aja, 2010), que consideran que elevados porcentajes de población envejecida o nacida fuera de España, generalmente poseen diversidad de carencias. Los enclaves revelados como desfavorecidos mediante este método, que ocupan 90 SSCC y $7.4 \mathrm{~km}^{2}$, así como sus 95,115 habitantes, permanecerían invisibles si no son tenidos en cuenta estos factores de vulnerabilidad, tratándose de población claramente vulnerable.

Para el análisis cluster se ha optado por hacer una selección de variables, desechando aquellas con severas lagunas o ausencia de información y las redundantes, determinadas por su coeficiente de correlación. Teniendo en cuenta estos aspectos, se parte de diez indicadores. Los que se encuentran relacionados entre sí han sido agrupados en cinco ejes básicos. Siguiendo las prácticas de otros autores en la elaboración de sus clusters, para cada agrupación adoptada se ha elaborado un índice por diversos métodos:

- Envejecimiento: Los indicadores "mayores de 75 años" y "hogares unipersonales con mayores de 65 años" se sintetizan en un componente principal.

- Carencias laborales-económicas: Los indicadores "ocupados sin cualificar" y "tasa de paro" se sintetizan en un componente principal.

- Reducido nivel educativo: Única dimensión con una sola variable. Se crea un índice básico tipificando "analfabetos o sin estudios mayores 
Vulnerabilidad urbana desapercibida e incertidumbre de los métodos estadísticos de identificación / J. GARCÍA y J.L. GARCÍA

Figura 4: Secciones censales vulnerables en Valladolid según Análisis de Componentes Principales

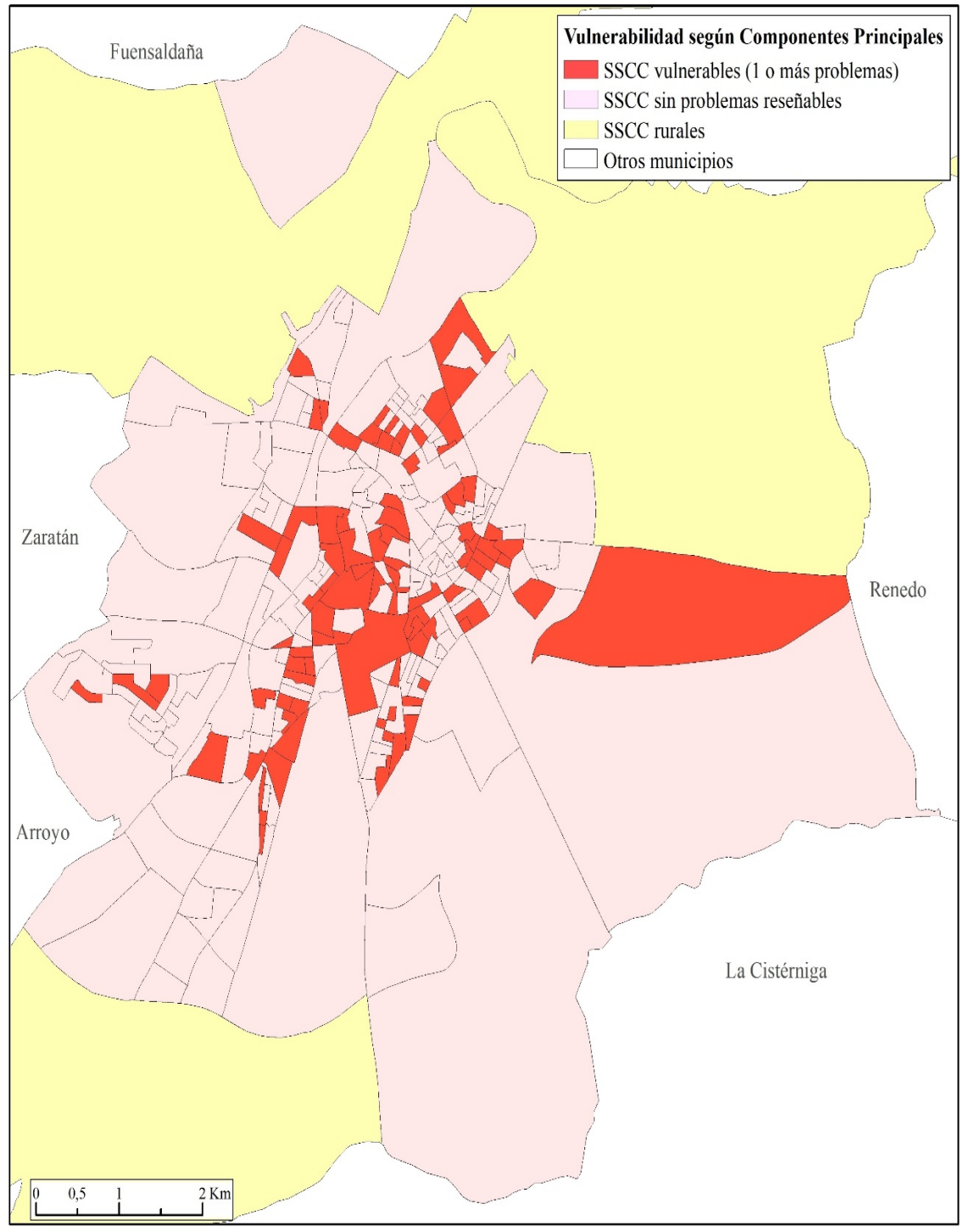

Fuente: elaboración propia (INE, 2019). 
de 16 ", restando la media del indicador a cada valor y dividiendo el resultado por la desviación típica.

- Viviendas en mal estado y/o con carencias sanitarias: Las variables "sin baño o ducha", "sin aseo o inodoro" y "en ruina" se sintetizan en dos componentes. A continuación, se realiza la media aritmética de ambos componentes.

- Hacinamiento: al indicador "superficie media por habitante" se le realiza un inverso multiplicativo.

El análisis cluster se ha efectuado a través del método jerárquico y del sistema Ward de conglomeración, con la distancia euclídea como intervalo. Atendiendo a la alteración de coeficientes del historial de conglomeración y a los conglomerados del dendograma, se ha optado por una solución de siete clusters. Los niveles de vulnerabilidad se han establecido en función de la media de las SSCC que están agrupadas en cada eje. Se otorga una posición ordinal para cada dimensión según el alejamiento de la media, de forma que la séptima posición es para el cluster más alejado negativamente, con SSCC en peor situación en cada dimensión.

Por contra, el cluster con SSCC en mejor situación, recibe la primera posición. Apreciando una concepción multidimensional de la vulnerabilidad, se suman las posiciones de forma que la puntuación es más elevada a mayor vulnerabilidad. En función de las posiciones de cada cluster en cada dimensión y derivado de la suma de posiciones, se aplica un nivel de vulnerabilidad acorde a la leyenda de la Tabla 4. Cada cluster tiene una posición global y posiciones individuales en cada dimensión, que diferencian problemas inherentes a cada espacio. De los siete rangos establecidos, se estiman reseñables los niveles: severo y elevado.

El resultado del análisis cluster muestra rangos de vulnerabilidad de cada una de las 270 SSCC con respecto al resto de la ciudad. Un total de 235 tienen carencias reseñables en alguno de los aspectos examinados, mientras que tan solo 35 no tienen ningún problema. 17 SSCC se encuentran en riesgo severo por poseer carencias en todas las dimensiones, 70 observan carencias en cuatro de las cinco dimensiones, 91 en tres dimensiones y 57 en dos. 
Figura 5: Nivel de vulnerabilidad de Secciones censales en Valladolid según análisis clúster

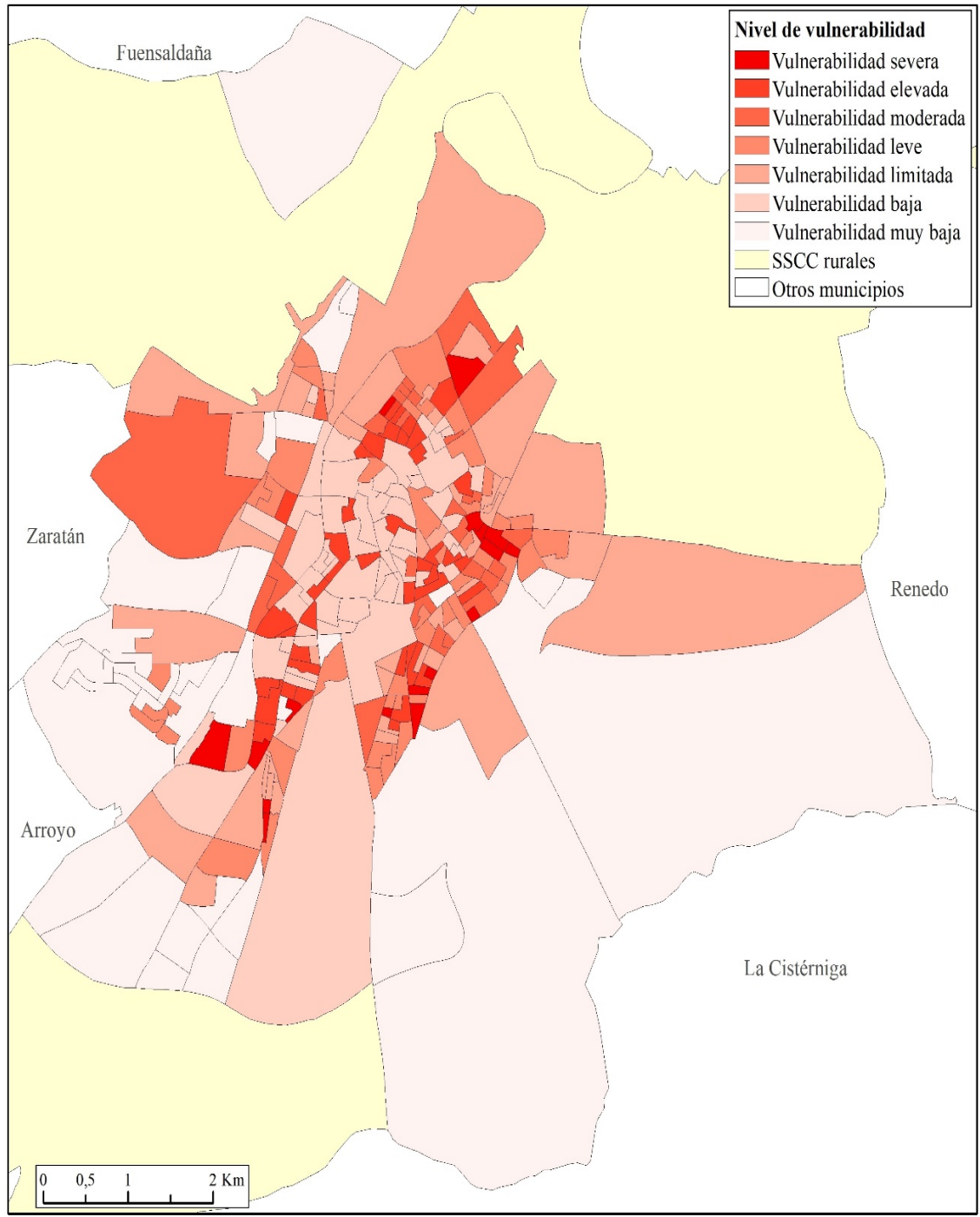

Fuente: elaboración propia. 


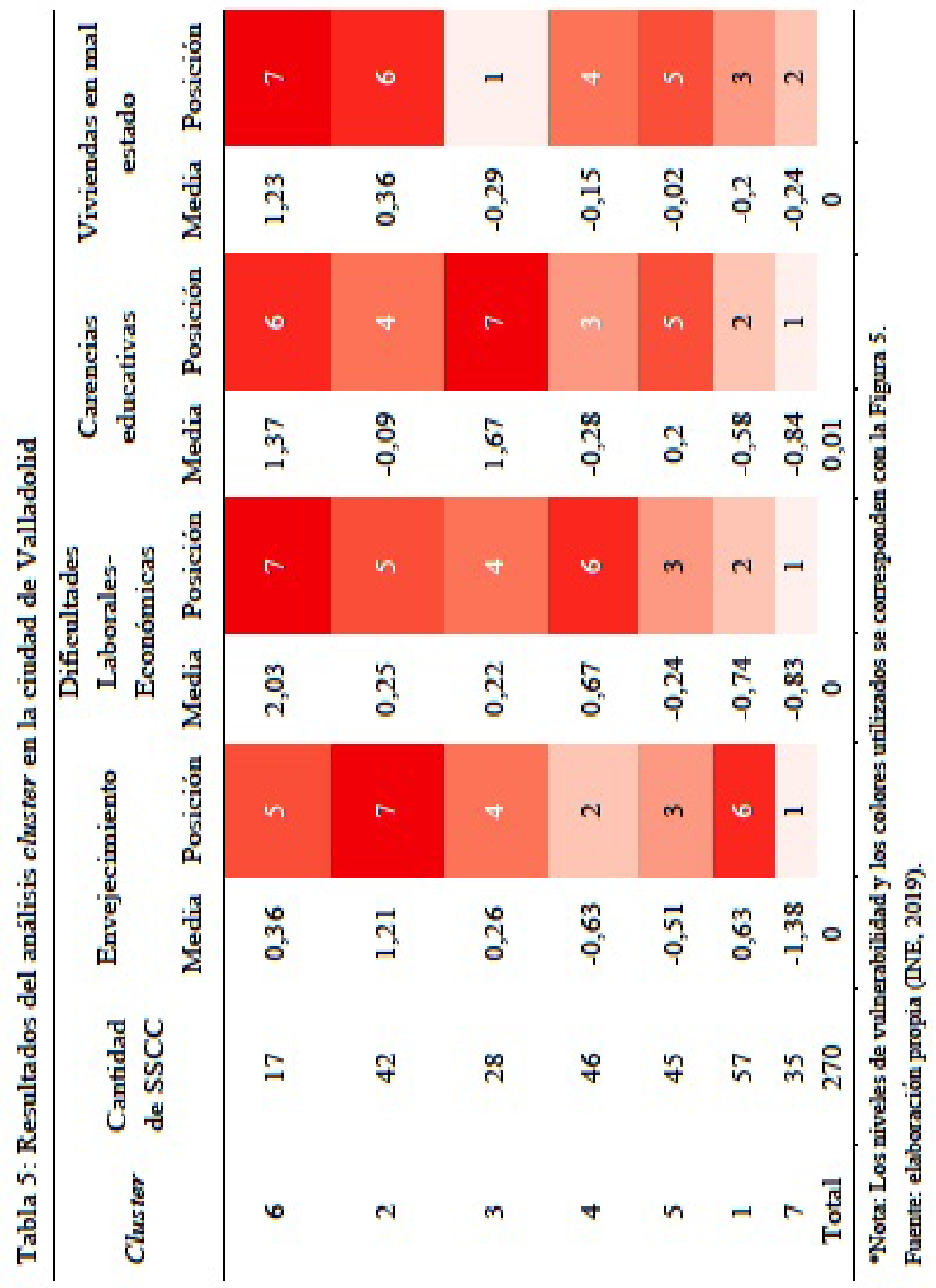


Vulnerabilidad urbana desapercibida e incertidumbre de los métodos estadísticos de identificación / J. GARCÍA y J.L. GARCÍA

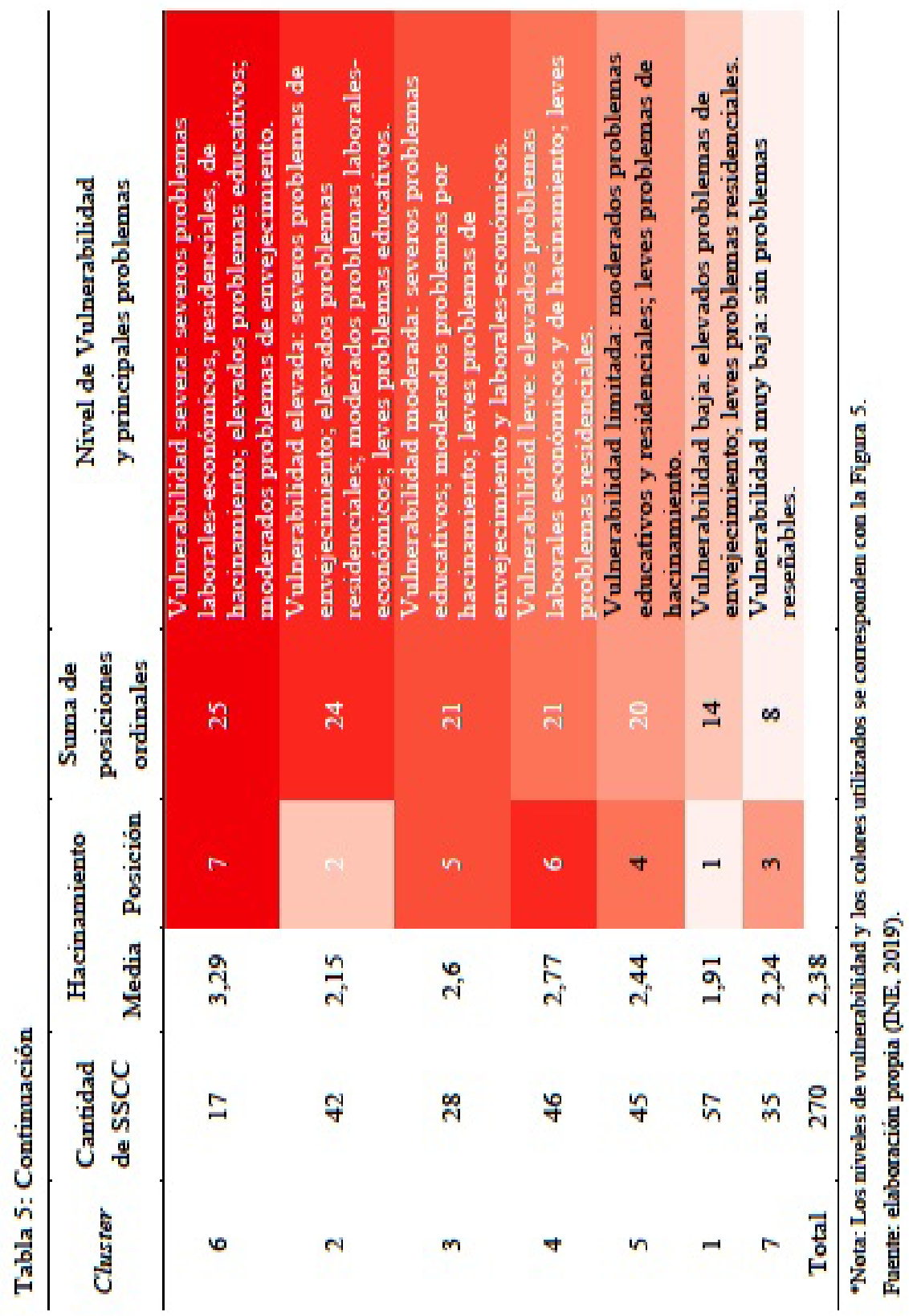


Con el método cluster nos encontramos de nuevo con resultados diferentes a los anteriores, con espacios que anteriormente habían sido estimados como altamente vulnerables, que son considerados ahora como de vulnerabilidad baja o limitada. De igual forma, se descubren SSCC con vulnerabilidad severa que no habían sido detectadas por otros métodos. Considerando las que tiene vulnerabilidad severa, nos encontramos con 17, en las que viven 17,900 personas. Si se opta por tener en cuenta la vulnerabilidad severa y elevada, dado que en la Tabla 5 se observa una suma de posiciones ordinales muy similar, destacan 59 SSCC y 58,490 personas.

\section{SínTESIS DE RESULTADOS}

La disparidad de resultados en función del procedimiento elegido para identificar vulnerabilidad urbana resulta irrebatible, como puede comprobarse en la Tabla 6. La similitud de los métodos debiera arrojar resultados parecidos, aunque se produjesen inevitables desfases que, en buena lógica, debieran consistir tan solo en una o dos SSCC de diferencia y unos pocos miles de personas. No obstante, llega a afectar a 31.13 por ciento de la población en el peor de los casos, y a 5.86 por ciento en la mejor situación. A su vez, la superficie afectada por esta problemática también difiere de forma considerable, al oscilar entre 12.67 y 1.03 por ciento del territorio urbano vallisoletano.

El método de componentes principales es el que identifica mayor cantidad de población vulnerable al tener en cuenta el envejecimiento y la población extranjera, que no son consideradas en otros casos. Se deduce, por tanto, que a mayor cantidad de variables la posibilidad de localizar población desfavorecida es mayor. El método cluster incluye también el envejecimiento, no obstante, la cantidad de población vulnerable en este caso depende más bien del nivel de restricción que se quiera decidir en el momento de disponer cuales son los clusters vulnerables. Se hace necesario destacar la redelimitación efectuada para dilucidar los barrios vulnerables que ofrece el Ministerio de Fomento en el Observatorio de la Vulnerabilidad Urbana, que rechaza decenas de SSCC por no tener entre 3,500 y 15 mil habitantes o por no tener continuidad arquitectónica. En definitiva, se ha puesto de manifiesto una inmensa variabilidad de resultados en función del método de identificación empleado que, en todo caso, deja de lado a población que puede detectarse por otros métodos. Por tanto, la identificación no es perfecta, al poder variar en función de mínimos cambios en el método o en los indicadores seleccionados. 
Tabla 6: Cuadro resumen de resultados: identificación de la vulnerabilidad en Secciones Censales (SSCC) de la ciudad de Valladolid, 2011*

\begin{tabular}{lrrrrr}
\hline $\begin{array}{l}\text { Metodología de identificación } \\
\text { de la vulnerabilidad }\end{array}$ & $\begin{array}{r}\text { Número } \\
\text { de SSCC }\end{array}$ & Población & $\begin{array}{r}\text { Superficie } \\
\left(\mathrm{km}^{2}\right)\end{array}$ & $\begin{array}{r}\% \text { de } \\
\text { población } \\
\text { s/ total }\end{array}$ & $\begin{array}{r}\% \text { de } \\
\text { superficie } \\
\text { s/total }\end{array}$ \\
\hline $\begin{array}{l}\text { SSCC que superan valor de } \\
\text { referencia en al menos un IBVU }\end{array}$ & 47 & 46.960 & 4,59 & 15,37 & 7,75 \\
$\begin{array}{l}\text { Barrios vulnerables según } \\
\text { redelimitación del EAVCE }\end{array}$ & 31 & 21.970 & 1,32 & 7,19 & 2,23 \\
$\begin{array}{l}\text { SSCC con media de IBVU } \\
\text { en el cuarto cuartil (método IDH) }\end{array}$ & 65 & 68.690 & 7,5 & 22,48 & 12,67 \\
$\begin{array}{l}\text { SSCC 1,5 veces sobre desviación } \\
\text { típica en algún componente }\end{array}$ & 90 & 95.115 & 7,48 & 31,13 & 12,63 \\
$\begin{array}{l}\text { SSCC en el cluster más } \\
\text { desfavorecido }\end{array}$ & 17 & 17.900 & 0,61 & 5,86 & 1,03 \\
$\begin{array}{l}\text { SSCC en los dos clusteres } \\
\text { más desfavorecidos }\end{array}$ & 59 & 58.490 & 2,01 & 19,14 & 3,39 \\
$\begin{array}{l}\text { Población de VA en SSCC } \\
\text { urbanas }\end{array}$ & 305.575 & & & & \\
$\begin{array}{l}\text { Superficie de VA en SSCC } \\
\text { urbanas }\end{array}$ & 59,2 & & & & \\
\hline
\end{tabular}

*Datos estimados de Barrios vulnerables según redelimitación del EAVCE, al no coincidir la delimitación de algunos barrios con SSCCs.

Fuente: elaboración propia (INE, 2019).

\section{Conclusiones}

Tras dividir una ciudad de tamaño intermedio en espacios en función del grado de vulnerabilidad de sus habitantes, se concluye que existe gran diferencia entre los resultados obtenidos en relación con los indicadores y la metodología diferenciadora utilizados. Considerando la falta de acuerdo para medir la vulnerabilidad centrada en ambos aspectos, se advierte que pueden quedar colectivos fuera de cada identificación. Por una parte, se plantea un problema con los indicadores relativo a la obtención de datos supramunicipales, a lo que se debe sumar la aparición de nuevas realidades y problemáticas que obligan a revisar los valores usados. Por otra parte, se plantea una duda sobre las metodologías o instrumentos a utilizar. Aún en el caso de que puedan recopilarse datos a escala supramunicipal, se ha descubierto que cada método empleado arroja resultados diferentes con los mismos datos. Semejante tesitura invita a pensar que, en todos los casos analizados, pueden quedar espacios vulnerables sin detectar. A esta constatación no deben dejar de unirse todas las demás posibilidades de vulnerabilidad desapercibida mencionadas con anterioridad. 
Es preciso reiterar que, en ocasiones, la invisibilidad puede ser indetectable en un análisis estadístico, por muy detallado que sea. No es necesario incidir en la imposibilidad de encontrar vulnerabilidad extrema en SSCC, aunque se hace necesario reseñar su existencia, al igual que aquella silenciosa, que no se ve o se desconoce, que puede acaecer en zonas que no llaman la atención y hacer que residentes en viviendas legales o en barrios sin problemas, presenten necesidades, materiales o inmateriales. En consecuencia, y por todo ello, se considera que la vulnerabilidad desapercibida puede pasar inadvertida si no se investiga de forma exclusiva.

Ninguno de los métodos propuestos debe ser considerado mejor o peor que los demás, sino valorado como una muestra de la dificultad de cuantificar fenómenos multidimensionales mediante métodos estadísticos. No obstante, se estima que a pesar de que existiera consenso sobre la forma de medir la vulnerabilidad en ciudades, no significaría que la metodología por la que se optara fuera la adecuada, ya que siempre se corre el riesgo de no detectar determinados entornos en toda investigación estadística. Bien es cierto que los espacios más vulnerables de la ciudad de Valladolid aparecen reseñados de forma repetida en todos los métodos empleados, por lo que se puede decir que la reiteración metodológica permite detectar los espacios más vulnerables para los que se disponga de información estadística.

Es posible que deba replantearse la forma de identificar la vulnerabilidad urbana. Al margen del amplio debate existente sobre la utilización de metodologías cualitativas o cuantitativas, se puede afirmar que la aproximación cuantitativa no resulta adecuada. La razón de ser de los análisis estadísticos es la precisión, y la ciencia positivista tiene entre sus principios fundamentales la exactitud, por lo que mientras no se tengan datos precisos a escalas menores que las SSCC, la identificación cuantitativa de espacios vulnerables se revela como una aproximación a la realidad social de las ciudades, que permite hacerse una idea imprecisa de la situación.

Ateniéndonos exclusivamente al análisis de la bibliografía que infiere en la detección y posterior estudio de espacios vulnerables, así como a la identificación efectuada en Valladolid, se deduce que en muchos casos se entiende la necesidad de recurrir a los métodos subjetivos para conocer los espacios detectados, es decir, para conocer la realidad. Es apreciado como necesario aplicar el análisis cualitativo para conocer a las personas y colectivos, una vez detectados, como demuestran los estudios de caso de espacios vulnerables efectuados con objeto de comprender la realidad. Si se entiende que es preciso recurrir a ello para conocer la realidad de colectivos y espacios vulnerables, y para comprender la lógica de un territo- 
rio ¿porque no usarlo para conocer y comprender una ciudad? En España, únicamente el EAVCE recurre al análisis cualitativo para delimitar -más bien redelimitar-, lo cual debe ser sopesado como un hecho de gran trascendencia. A pesar de contar con el inconveniente de señalar únicamente los espacios entre 3,500 y 15 mil habitantes, la idea es sumamente adecuada. Se valora inconveniente el establecimiento de dicho rango y el haber acudido únicamente a un técnico municipal para redelimitar. Se juzga más adecuado recurrir a diferentes agentes, pertenecientes a diferentes ámbitos y relacionados con el espacio estudiado.

Ante los problemas que plantean las metodologías identificativas, entre los que destaca la falta de consenso y los desiguales resultados que arroja cada una de ellas, la solución podría pasar por utilizar una fórmula diferente. Se puede partir directamente de una interpretación subjetiva sistematizada, que ubique vulnerabilidad desapercibida en entornos que hasta ahora quedan fuera de las estadísticas oficiales. Puede establecerse un método que, a pesar de ser subjetivo, puede ser generalizable, basado en una batería de preguntas únicas y un modelo de agentes a entrevistar, formado por personas que conozcan la realidad social y estén en contacto con ella. En definitiva, se trataría de elegir entre la cantidad de datos y la forma de tratarlos, o su calidad. Ha quedado claro que la forma existente para detectar espacios vulnerables no consigue su objetivo, por lo que se plantea una nueva perspectiva que puede no ser perfecta, a falta de desarrollarla, pero que puede significar un avance en la erradicación de la vulnerabilidad desapercibida.

\section{REFERENCIAS BIBLIOGRÁFICAS}

Alguacil, J., 2006, "Barrios desfavorecidos: diagnóstico de la situación española", en García, J. et al. (eds.), V Informe FUHEM de políticas sociales: La exclusión social y estado del bienestar en España, Funhem, Madrid, 155-168.

Alguacil, J., Camacho, J. y Hernández, A., 2014, "La vulnerabilidad urbana en España. Identificación y evolución de los barrios vulnerables", en Empiria, núm. 27, 73-94. doi: https://doi.org/10.5944/empiria.27.2014.10863

Alzola, M., 2011, Diagnóstico de las necesidades de intervención en la renovación del parque edificado de Euskadi, Tecnalia Research Innovation, Bizkaia.

Arcos, E., Canales, M., Muñoz, L. A., Toffoletto, M. C., Sánchez, X. y Vollrath, A., 2016, "Invisibilidad de la vulnerabilidad social y derecho al cuidado de salud integral en Chile", en Texto Contexto Enferm, núm. 25(4), 1-8. doi: http://dx.doi. org/10.1590/0104-07072016006150015

Ayuntamiento de Alicante, 2008, Plan integral de recuperación barrios zona norte de Alicante, Concejalía de Presidencia de Alicante, Alicante. 
Beytía, P., 2012, La pobreza invisible. Sobre la satisfacción con la vida en los campamentos de Chile, Centro de Investigación Social de TECHO, Santiago de Chile.

Calvo, F., 1984, "Geografía de los riesgos", en Cuadernos críticos de geografía humana, núm. 54, 1-37. Disponible en: http://www.ub.edu/geocrit/geo54.htm

Castells, M., 2005, “Globalización e identidad”, en Cuadernos del Mediterráneo, núm. $5,11-20$.

Castanyer, J. V., Rufí, J., Feliu, R. y Martín, J., 2007, Nuevos escenarios urbanos: nuevos conflictos y nuevas politicas, Documenta Universitaria, Girona.

Comisión Europea, 1994, Libro blanco sobre política social europea, Oficina de publicaciones de comunicaciones europeas, Bruselas.

Comisión Europea, 2010, Estrategia Europea 2020: una estrategia para un crecimiento inteligente, sostenible e integrador, Oficina de publicaciones de comunicaciones europeas, Bruselas.

Commins, P., 1993, Combating exclusion, Dublin Travellers Education and Development Group, Dublin.

Consejería de Integración Social de la Comunidad de Madrid, 1990, "Decreto 73/1990, de 19 de julio, por el que se aprueba el ingreso madrileño de integración”, en Boletín Oficial de la Comunidad de Madrid de 25-7-1990, Madrid.

Domínguez-Berjón, M. F., et al., 2008, Construcción de un índice de privación a partir de datos censales en grandes ciudades españolas, en Gaceta Sanitaria, núm. 22(3), 179-187. Disponible en http://scielo.isciii.es/scielo.php?script=sci arttext\&pid=S0213-91112008000300002

Domínguez, J., Egea, C., González, R. y Nieto, C. J., 2008, Vulnerabilidad del tejido social de los barrios desfavorecidos de Andalucía, Centro de Estudios Andaluces, Sevilla.

Domínguez, J., Egea, C., González, R., Nieto y C. J., 2009, "Viejas y nuevas realidades urbanas. Identificación de habitabilidad desfavorecida en la ciudad de Granada", en Cuadernos geográficos, núm. 45, 83-105. Disponible en https://revistaseug.ugr.es/index.php/cuadgeo/article/view/758/844

Doyal, L. y Gough, I., 1991, A theory of human need, The Guilford Press, New York.

Durán, C. A., 2017, “Análisis espacial de condiciones de vulnerabilidad social, económica, física y ambiental en territorio colombiano", en Perspectiva geográfica, núm. 22(1), 11-32. Disponible en http://www.scielo.org.co/pdf/pgeo/ v22n1/0123-3769-pgeo-22-01-00011.pdf

Fuentes, M., 2011, Diagnóstico de barrios desfavorecidos en la ciudad de Sevilla, REDES Sevilla, Sevilla.

Harvey, D., 1977, Urbanismo y desigualdad social, Siglo XXI editores, Madrid. 
Hernández Aja, A., 1997, Análisis urbanístico de barrios vulnerables en España: informe general 1991, Ministerio de Fomento e Instituto Juan de Herrera, Madrid.

Hernández Aja, A., 2006, Análisis urbanístico de barrios vulnerables. Adenda 2006, Ministerio de Fomento e Instituto Juan de Herrera, Madrid.

Hernández Aja, A., 2007, Áreas vulnerables en el centro de Madrid, Instituto Juan de Herrera, Madrid.

Hernández Aja, A., 2010, Análisis urbanístico de barrios vulnerables en España: informe general 2001, Ministerio de Fomento e Instituto Juan de Herrera, Madrid.

Homobono, J., 2009, "Evolución y renovación de las ciudades. Selección de textos de Élisée Reclus”, en Zainak, núm. 31, 117-211. Disponible en http://hedatuz. euskomedia.org/8354/1/3101170211.pdf

Instituto Nacional de Estadística (INE), 2019, Censo de población y viviendas 2011, Instituto Nacional de Estadística (INE), Fecha de consulta 24/06/2021, disponible en http://www.ine.es/censos2011_datos/cen11_datos_resultados.htm

Instituto Nacional de Estadística, 2018, Indicadores de calidad de vida: Metodología, Instituto Nacional de Estadística (INE), Madrid.

Jiménez-Ridruejo, Z. (Coord.), 2010, El efecto de la situación social de los inmigrantes sobre su comportamiento laboral y repercusiones en la afiliación a la seguridad social, Ministerio de Trabajo e Inmigración, Madrid.

Kuznets, S., 1934, "Ingreso nacional 1929-1932”, en Documento del Senado de Estados Unidos, núm. 124, día 73, segunda sesión, Washington.

Laparra, M., Aguilar, M. y Gaviria, C., 1996, "Peculiaridades de la exclusión en España: propuesta metodológica y principales hipótesis a partir del caso de Aragón”, en Aguilar, M. (Coord.), Pobreza, necesidad y discriminación, Fundación Argentaria, 65-102, Madrid.

Laparra, M. y et al., 2007, "Una propuesta de consenso sobre el concepto de exclusión”, en Revista española del tercer sector, núm. 5, 15-59. Disponible en https:// dialnet.unirioja.es/servlet/articulo?codigo $=2376685$

Llano, J., 2017, El estado de la pobreza. Seguimiento del indicador de riesgo de pobreza y exclusión social en España, EAPN España, Madrid.

Llop, J. y Hoeflich, S. (Coords.), 2016, Documento marco de CGLU para ciudades intermedias, United Cities and Local Governments, Lleida.

Lorenzo, F., 2014, VI Informe sobre exclusión social y desarrollo en España, Fundación FOESSA, Cáritas española, Madrid.

Malgesini, G., 2013, Informe Anual sobre la Vulnerabilidad Social 2011-2012, Cruz Roja Española, Madrid.

Menchaca, E., Cervantes, D. y Bueno, E., 2010, Indicadores sociales y vulnerabilidad social: Una mirada a los problemas urbanos en la ciudad de Zacatecas, Asociación latinoamericana de población, Río de Janeiro. 
Metzger, P. y D’Ercole, R., 2009, “Los mecanismos de transmisión de vulnerabilidad en el medio urbano. Primeros elementos de reflexión", en Bulletin de l'Institut Français d'Études Andines, núm. 38(3), 917-936. doi: https://doi.org/10.4000/ bifea. 2570

Ministerio de Fomento, Gobierno de España, 2019, Atlas de la vulnerabilidad urbana 2001 y 2011, Fecha de consulta 24/06/2021, disponible en https://www. mitma.gob.es/areas-de-actividad/arquitectura-vivienda-y-suelo/urbanismo-y-politica-de-suelo/observatorio-de-la-vulnerabilidad-urbana/atlas-de-la-vulnerabilidad-urbana/atlas-de-las-vulnerabilidad-urbana-en-espan $\% \mathrm{CC} \% 83 \mathrm{a}$

Ministerio de Sanidad, Servicios Sociales e Igualdad (MSSSI), 2014, Plan Nacional de Acción de Inclusión Social del Reino de España 2013-2016, Centro de publicaciones del Ministerio de Sanidad, Servicios Sociales e Igualdad (MSSSI), Madrid.

Naciones Unidas, 2003, Informe sobre la situación social en el mundo, 2003. Vulnerabilidad social: Fuentes y desafios, United Nations Publications, New York.

Navarro, S. y Larrubia, R., 2006, "Indicadores para medir situaciones de vulnerabilidad social. Propuesta realizada en el marco de proyecto europeo", en Baetica, núm. 28, 485-506.

OECD, 1998, Integrating distressed urban areas, OECD, Paris. doi: https://doi. org/10.24310/BAETICA.2006.v1i28.270

Palacios, A. J., 2005, Barrios desfavorecidos urbanos: de la identificación a la intervención. Madrid como laboratorio, Tesis doctoral inédita, Repositorio Universidad Autónoma de Madrid, Departamento de Geografía, Madrid.

Paugam, S., 1996, L'exclusion, l'etat des saviors, La Découverte, París.

Pérez, V., 2007, Estudio sobre los barrios desfavorecidos de Madrid, Fundación de Estudios Ciudadanos, Madrid.

Piñeira, M., González, J. y Lois, R. C., 2017, "Vulnerabilidad urbana y exclusión. La fragmentación social de la ciudad postcrisis", en Castanyer, M., Rufí, J., Feliu, J. y Martín, J. (eds), Nuevos escenarios urbanos: nuevos conflictos y nuevas politicas, Documenta Universitaria, Girona, 75-91.

Pizarro, R., 2001, La vulnerabilidad social y sus desafios: una mirada desde América Latina, CEPAL, Santiago de Chile.

Real Academia Española (RAE), 2017, Diccionario de la lengua española. Actualización 2017, Fecha de consulta: 24/06/2021, disponible en https://dle.rae.es/

Red Andaluza de Lucha Contra la Pobreza y la Exclusión Social (EAPN-A), 2016, La pobreza invisible, EAPN-A, Sevilla.

Ruiz, N., 2011, "La definición y medición de la vulnerabilidad social. Un enfoque normativo", en Investigaciones Geográficas, núm. 77, 63-74. Disponible en http:// www.investigacionesgeograficas.unam.mx/index.php/rig/article/view/31016

Schalock, R. L. y Keith, K. D., 1993, Quality of life questionnaire manual, IDS Publishing Corporation, Worthington. 
Subirats, J. y Martí-Costa, M., 2014, Ciudades, vulnerabilidades y crisis en Espa$\tilde{n} a$, Centro de estudios andaluces, Sevilla.

Temes, R., 2014, "Valoración de la vulnerabilidad integral en las áreas residenciales de Madrid", en EURE-Revista Latinoamericana de Estudios Urbanos y Regionales, núm. 40, 119-149. doi: http://dx.doi.org/10.4067/S0250-71612014000100006

U1 Haq, M., 1990, Desarrollo humano: informe 1990, Tercer mundo, Bogotá.

UNRISD, 1972, Contents and Measurement of Socio-Economic Development: A Staff Study, Praeger, New York.

Uceda, P., 2016, La ciudad desequilibrada. El Derecho a la Ciudad en los barrios vulnerables de Madrid, Tesis doctoral inédita, Repositorio Universidad Complutense de Madrid. Madrid.

Verdugo, M. A., Arias, B., Gómez, L. E. y Schalock, R. L., 2007, “Construcción de escalas de calidad de vida multidimensionales centradas en el contexto: la Escala gencat", en Siglo Cero, núm. 38(4), 57-72. Disponible en https://www.researchgate.net/publication/236117357_Construccion_de_escalas_de_calidad_de_vida multidimensionales_centradas_en_el_contexto_la_Escala_GENCAT

\section{RESUMEN CURRICULAR DE LOS AUTORES}

Jesús García Araque

Doctor en Geografía, contratado postdoctoral y profesor en el Departamento de Geografía de la Universidad de Valladolid (UVa) desde 2018. Ha obtenido los premios extraordinarios en el Grado de Geografía y Ordenación del Territorio y en el Máster en Desarrollo Económico Regional y Local y Gestión del Territorio. Ha participado en congresos y tiene publicaciones relacionadas con la vulnerabilidad, la exclusión y las políticas sociales. Colaborador en el proyecto nacional de investigación INCLUSIVE, con el Departamento de Sociología de la UVa y actualmente miembro del Grupo de Investigación Reconocido (GIR) CITERIOR y del Instituto Universitario de Urbanística.

Dirección electrónica: jesus.garcia@uva.es

ORCID ID: https://orcid.org/0000-0002-4112-9404

\section{José Luís García Cuesta}

Doctor en Geografía. Profesor Titular de Geografía Humana de la Universidad de Valladolid (UVa). Premio Extraordinario de Licenciatura y Premio Extraordinario de Doctorado. Docente desde 1994 en Licenciaturas, Grados, Máster y Doctorado. Las principales líneas de investigación son: procesos urbanos relacionados con la actividad inmobiliaria, el mercado de suelo y vivienda y las transformaciones recientes; patrimonio territorial en 
todas sus dimensiones; actividad turística y turismo de interior. Investigador principal y miembro del equipo de investigación en varios proyectos de convocatorias competitivas, y en diversos contratos con administraciones y empresas. Autor de libros, capítulos de libros, artículos e informes, ha impartido conferencias y cursos de máster y doctorado en distintas universidades españolas, europeas y latinoamericanas. Miembro de comités de revistas científicas (algunas indexadas) y evaluador en muchas de ellas. Director del Laboratorio de Cartografía y SIG y Coordinador del GIR CITERIOR, ambos de la UVa.

Dirección electrónica: josgar@fyl.uva.es

ORCID ID: https://orcid.org/0000-0002-9217-9436 